\title{
The Emergence of Actinide Cyclobutadienyl Chemistry
}

DOI:

10.1002/ejic.202000383

\section{Document Version}

Accepted author manuscript

Link to publication record in Manchester Research Explorer

\section{Citation for published version (APA):}

Boronski, J., \& Liddle, S. (2020). The Emergence of Actinide Cyclobutadienyl Chemistry. European Journal of Inorganic Chemistry. https://doi.org/10.1002/ejic.202000383

\section{Published in:}

European Journal of Inorganic Chemistry

\section{Citing this paper}

Please note that where the full-text provided on Manchester Research Explorer is the Author Accepted Manuscript or Proof version this may differ from the final Published version. If citing, it is advised that you check and use the publisher's definitive version.

\section{General rights}

Copyright and moral rights for the publications made accessible in the Research Explorer are retained by the authors and/or other copyright owners and it is a condition of accessing publications that users recognise and abide by the legal requirements associated with these rights.

\section{Takedown policy}

If you believe that this document breaches copyright please refer to the University of Manchester's Takedown Procedures [http://man.ac.uk/04Y6Bo] or contact uml.scholarlycommunications@manchester.ac.uk providing relevant details, so we can investigate your claim.

\section{OPEN ACCESS}




\section{The Emergence of Actinide Cyclobutadienyl Chemistry}

\author{
Josef T. Boronski ${ }^{[a]}$ and Stephen T. Liddle ${ }^{*[a]}$
}

\begin{abstract}
Since its inception in the 1950s, the field of organoactinide chemistry has developed and is still burgeoning today. A plethora of molecular actinide cyclopentadienyl $\left(C_{5}\right)$, arene $\left(C_{6}\right)$, cycloheptatrienyl $\left(C_{7}\right)$, and cyclooctatetraenyl $\left(C_{8}\right)$ complexes are known. However, the first f-element cyclobutadienyl complex, a uranium derivative, was only reported as recently as 2013, which contrasts to transition metal chemistry where the first cyclobutadienyl derivatives were realised in the 1950s. A small but growing number of uranium and thorium cyclobutadienyl complexes are now known, so now is an opportune time to review progress to date. This Minireview addresses bonding considerations for the cyclobutadienyl ligand, surveys synthetic routes to crystallographically authenticated actinide cyclobutadienyl complexes and their novel bonding features, and highlights future directions that merit development.
\end{abstract}

Josef T. Boronski was awarded his MChem (Hons) in 2017 from the university of York. His $4^{\text {th }}$ year masters research project involved the study of novel low-oxidation state gallium species, under the supervision of $\mathrm{Dr}$ John Slattery. Subsequently, he began a PhD with Prof Liddle at The University of Manchester, investigating the chemistry of actinidecarbene and -cyclobutadienyl complexes.

Stephen T. Liddle is Professor and Head of Inorganic Chemistry at The University of Manchester. $\mathrm{He}$ is also co-director, Centre for Radiochemistry Research, and currently holds an EPSRC Established Career Fellowship. His research interests span $f$ and early $d$-block coordination and organometallic chemistry supported by polyanionic ligands, most prominently including metal-ligand multiple bonding, small molecule activation and catalysis, and single molecule magnets.

\section{Introduction}

In 1956, Longuet-Higgins and Orgel predicted the existence of stable transition metal complexes of the four-membered carbocycle cyclobutadiene, $\mathrm{C}_{4} \mathrm{H}_{4} \cdot{ }^{[1]}$ Free cyclobutadiene is an unstable, rectangular organic molecule that has been isolated in matrices of noble gasses at $8-20 \mathrm{~K}^{\left[{ }^{[2]}\right.}$ The square form of cyclobutadiene is, by Hund's rule, a $4 \pi$-electron, anti-aromatic diradical that would be expected to distort to the rectangular singlet form. However, it was proposed that the two unpaired electrons of this species could form two m-bonds to a metal centre, thus stabilising the cyclobutadiene as a cyclobutadienyl. ${ }^{[1,3]}$ This prediction was subsequently proven correct when the first transition metal complex of a substituted cyclobutadienyl, [Fe $\left(\eta^{4}-\right.$ $\left.\left.\mathrm{C}_{4} \mathrm{Ph}_{4}\right)(\mathrm{CO})_{3}\right]$ (I), was structurally authenticated in $1960,{ }^{[4 \mathrm{a}]}$ and the first unsubstituted cyclobutadienyl complex, the quintessential $\left[\mathrm{Fe}\left(\eta^{4}-\mathrm{C}_{4} \mathrm{H}_{4}\right)(\mathrm{CO})_{3}\right](\mathrm{II})$, was reported by Pettit in 1965 (Figure 1). ${ }^{[\mathrm{bb}]}$

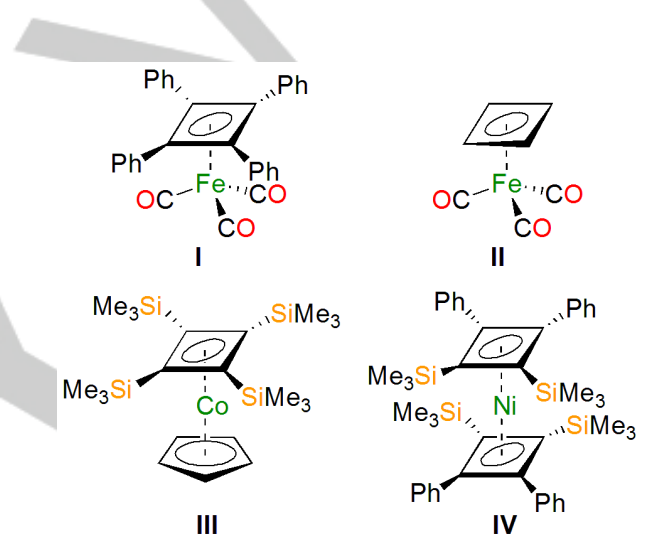

Figure 1. Key examples of transition metal-cyclobutadienyl complexes $\left[\mathrm{Fe}\left(\mathrm{n}^{4}\right.\right.$ $\left.\left.\mathrm{C}_{4} \mathrm{Ph}_{4}\right)(\mathrm{CO})_{3}\right](\mathrm{I}),\left[\mathrm{Fe}\left(\eta^{4}-\mathrm{C}_{4} \mathrm{H}_{4}\right)(\mathrm{CO})_{3}\right](\mathrm{II}),\left[\mathrm{Co}\left\{\eta^{4}-\mathrm{C}_{4}\left(\mathrm{SiMe}_{3}\right)_{4}\right\}\left(\mathrm{C}_{5} \mathrm{H}_{5}\right)\right]$ (III), and $\left[\mathrm{Ni}\left\{\eta^{4}-\mathrm{C}_{4} \mathrm{Ph}_{2}\left(\mathrm{SiMe}_{3}\right)_{2}\right\}_{2}\right]($ IV).

The chemistry of transition metal cyclobutadienyl complexes has become well-developed over the past sixty years. ${ }^{[5]}$ In addition to the well-represented $6 \pi$-electron $\left\{\mathrm{C}_{4} \mathrm{Ph}_{4}\right\}^{2-}$ cyclobutadienyl dianion, ${ }^{[6,7]}$ the silyl analogue, $\left\{\mathrm{C}_{4}\left(\mathrm{SiMe}_{3}\right)_{4}\right\}^{2-}$ can be constructed at cobalt using $\left[\mathrm{Co}\left(\eta^{5}-\mathrm{C}_{5} \mathrm{H}_{5}\right)(\mathrm{CO})_{2}\right]$ in a $[2+2]$-cycloaddition reaction to give $\left[\mathrm{Co}\left(\eta^{5}-\mathrm{C}_{5} \mathrm{H}_{5}\right)\left\{\eta^{4}-\mathrm{C}_{4}\left(\mathrm{SiMe}_{3}\right)_{4}\right\}\right]$ (III) (Figure 1). ${ }^{[7 a]}$ Most transition metal cyclobutadienyl complexes are half sandwich or heteroleptic sandwich complexes like III, but [Ni\{ $\eta^{4}-$ $\left.\mathrm{C}_{4} \mathrm{Ph}_{2}\left(\mathrm{SiMe}_{3}\right)_{2}\right\}_{2}$ ] (IV) is notable for being the only example to date of a structurally authenticated homoleptic bis(cyclobutadienyl) transition metal sandwich complex (Figure 1). ${ }^{[7 c]}$ The synthesis and study of such species has advanced our collective knowledge of transition metal bonding, as well as a better understanding of the reactivity and electronic structure of aromatic carbocycles. Historically, however, methods of constructing cyclobutadienyl rings at metals are low yielding, with the generation of multiple coproducts that complicates their syntheses and severely restricted progress. However, in 2000 Sekiguchi and co-workers reported that $\left[(\mathrm{Li})_{2}\left\{\mathrm{C}_{4}\left(\mathrm{SiMe}_{3}\right)_{4}\right\}(\mathrm{THF})_{2}\right](1 \mathrm{Li})$ can be isolated via treatment of III with lithium. ${ }^{[8 a]}$ Furthermore, it was discovered that 1 can be oxidised to neutral tetra(trimethylsilyl)cyclobutadiene $\left\{\mathrm{C}_{4}\left(\mathrm{SiMe}_{3}\right)_{4}\right\}$, which is a rectangular singlet. ${ }^{[8 c]}$ Both species are stable under 
ambient conditions, which has eased the difficulties in developing the area. ${ }^{[8]}$
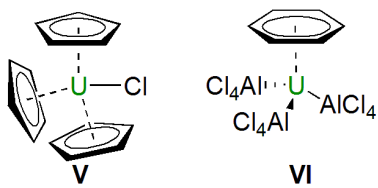

VI

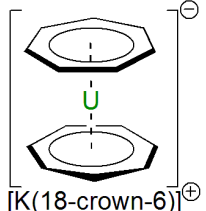

VII

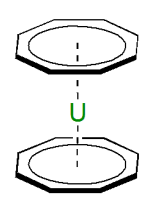

VIII

Figure 2. Key examples of uranium- $\eta^{n}$-carbocyclic complexes $\left[\mathrm{U}\left(\eta^{5}-\mathrm{C}_{5} \mathrm{H}_{5}\right)_{3} \mathrm{Cl}\right.$, $(\mathbf{V}),\left[\mathrm{U}\left(\eta^{6}-\mathrm{C}_{6} \mathrm{H}_{6}\right)\left(\mathrm{AlCl}_{4}\right)_{3}\right](\mathrm{VI}),\left[\mathrm{U}\left(\eta^{7}-\mathrm{C}_{7} \mathrm{H}_{7}\right)_{2}\right][\mathrm{K}(18-\mathrm{crown}-6)](\mathrm{VII})$, and $\left[\mathrm{U}\left(\eta^{8}-\right.\right.$ $\left.\left.\mathrm{C}_{8} \mathrm{H}_{8}\right)_{2}\right](\mathrm{VIII})$

The actinide metals play an essential role in the generation of civil nuclear energy, first established in the 1940s during the Manhattan Project. ${ }^{[9-11]}$ Knowledge of the chemical properties of these elements is critical in refinements to the nuclear fuel cycle, particularly regarding the reprocessing of spent nuclear fuel and the remediation of radioactive waste..$^{[9,11]}$ However, the chemistry of the actinides is rather complex, with marked differences in properties observed across the actinide series. ${ }^{[10,11]}$ The actinide valence $5 f$-orbitals possess a radial node, and due to high atomic $Z$ numbers experience an indirect relativistic orbital expansion, as do the $6 d$ orbitals. In combination, these effects lead to the $5 f$ and $6 d$ orbitals of the early actinides occupying a similar energetic range and spatial region. Therefore, both orbital sets have the potential to overlap with ligand orbitals, leading to a degree of covalent bonding character for early actinide coordination complexes. These factors also explain the wide range of oxidation states accessible for the early actinides. ${ }^{[10,11]}$

Despite its aforementioned significance, our understanding of actinide chemistry has historically lagged substantially behind that of the transition metals. ${ }^{[12]}$ Wilkinson and Birmingham reported the first organoactinide complex, $\left[\mathrm{U}\left(\eta^{5}-\mathrm{C}_{5} \mathrm{H}_{5}\right)_{3} \mathrm{Cl}\right](\mathbf{V})$ in 1956 (Figure 2). ${ }^{[12 a]}$ Since actinides ions are large, increasingly large

a)

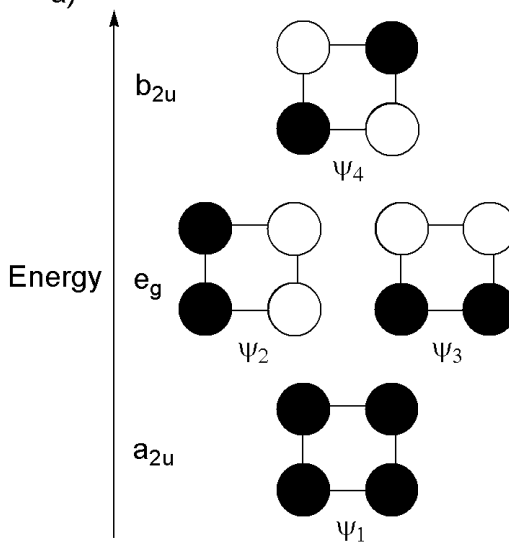

b)

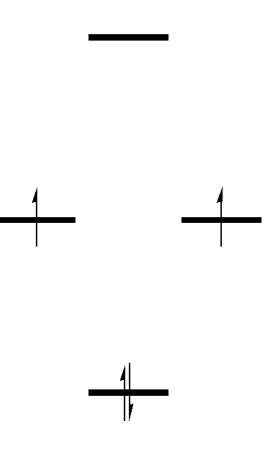

carbocyclic ligands can be accommodated, as exemplified by $\left[\mathrm{U}\left(\eta^{6}-\mathrm{C}_{6} \mathrm{H}_{6}\right)\left(\mathrm{AlCl}_{4}\right)_{3}\right](\mathrm{VI}),\left[\mathrm{U}\left(\eta^{7}-\mathrm{C}_{7} \mathrm{H}_{7}\right)_{2}\right][\mathrm{K}(18-c r o w n-6)](\mathbf{V I I})$, and $\left[\mathrm{U}\left(\eta^{8}-\mathrm{C}_{8} \mathrm{H}_{8}\right)_{2}\right](\mathrm{VIII})$ (Figure 2). ${ }^{[12,13]}$ The latter of these, uranocene, disclosed by Streitwieser in 1968 and structurally authenticated by Raymond in 1972, ${ }^{[13]}$ was a seminal discovery for f-element chemistry and organometallic chemistry more widely, because of its predicted four-fold symmetric bonding combinations with $f$ - and $d$-orbitals. ${ }^{[13,14]}$ Over the intervening decades, the field of actinide organometallic chemistry has undergone many advances, and a plethora of molecular actinide cyclopentadienyl $\left(\mathrm{C}_{5}\right)$, arene $\left(\mathrm{C}_{6}\right)$, cycloheptatrienyl $\left(\mathrm{C}_{7}\right)$, and cyclooctatetraenyl $\left(\mathrm{C}_{8}\right)$ complexes are known. ${ }^{[15]}$ However, only as recently as 2013 was the first $f$ element cyclobutadienyl $\left(\mathrm{C}_{4}\right)$ complexes reported, and such species remain exceedingly rare. ${ }^{[16,17]}$ The general paucity of actinide cyclobutadienyl chemistry most likely reflects the lack of suitable cyclobutadienyl transfer reagents. For example, effecting $[2+2]$-cycloadditions of alkynes to construct cyclobutadienyl ligands at metals that little enforce orbital control of reactivity is extremely challenging. Furthermore, as will become clear, cyclic cyclobutadienyl dianions are highly basic and reducing, and often self-deprotonate to generate cyclometallates and protonated $\mathrm{C}_{4}$ ring allyl-type species, or they promote undesirable redox reactions, usually the indiscriminate reduction of metal ions.

Since actinide cyclobutadienyl chemistry is beginning to emerge, now is an opportune time to review its progress to date. This Minireview will outline bonding considerations for the cyclobutadienyl ligand, survey crystallographically characterised examples of actinide cyclobutadienyl complexes, then highlight promising future directions for the area in which to develop. Given the still somewhat embryonic nature of the field, complexes will be discussed in chronological order by publication date in order to best illustrate developments in this field, since there are not yet enough examples to adopt more traditional taxonomic approaches.

Figure 3. Qualitative depictions of the relative energies of the frontier $\pi$-molecular orbital symmetry combinations for the cyclobutadienyl dianion $\left\{\mathrm{C}_{4} \mathrm{R}_{4}\right\}^{2-}$. a) symmetry combinations and labels. b) electron populations of the neutral triplet form. c) illustration of the distorted neutral singlet form form. d) electron populations of the singlet dianion form. 


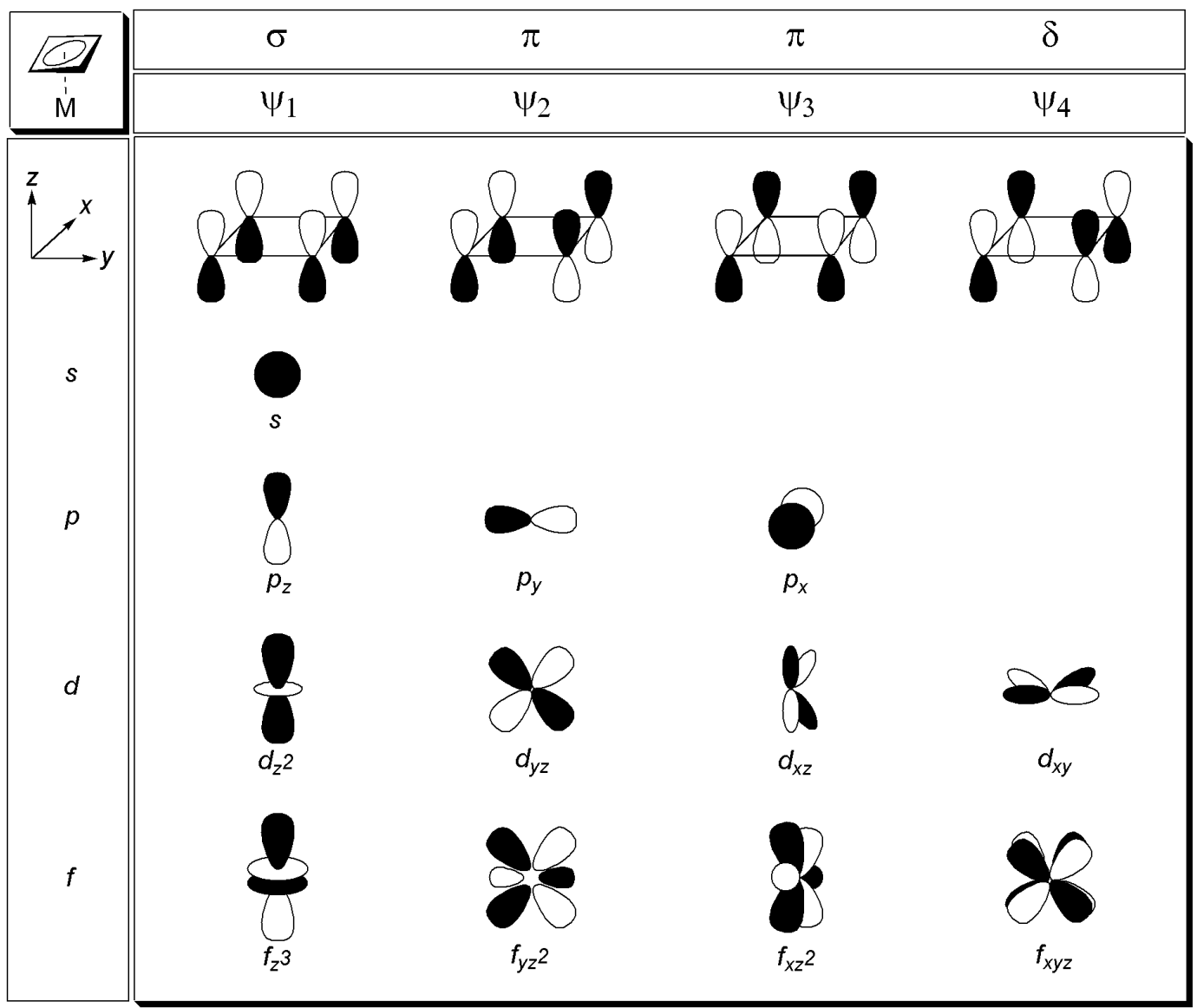

Figure 4. Molecular orbital combinations for metal-cyclobutadienyl bonding interactions, with metal-based s, p, d, and f-orbitals of correct symmetry. This figure is depicted according to a convention where for the $\pi$-bonding interactions the metal orbital lobes intersect between two carbon orbital lobes, but an equally valid model would be rotated by $45^{\circ}$ resulting in those metal orbitals interacting directly with the 1,3- or 2,4-carbon atom lobes. Though the details vary for the two descriptive visualisations, in that the metal and cyclobutadienyl orbital projections then change, the overall symmetry of the interactions in each model remains the same; for example, if the $\pi$-symmetry $d_{y z}$ and $d_{x z}$ orbitals were arbitrarily rotated by $45^{\circ}$ to align with the carbon atom lobes directly, the $d_{x z}$ orbital would

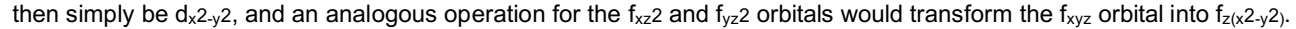

\section{Bonding Considerations}

Square cyclobutadiene ( $D_{4 \mathrm{~h}}$ point group) has four $\pi$ molecular orbitals, presented here in order of energy, lowest to highest: $\psi_{1}$ of a-symmetry, degenerate $\psi_{2}$ and $\psi_{3}$ of e-symmetry, and $\psi_{4}$ of $b$ symmetry (Figure 3a). ${ }^{[1,3,5]}$ For the neutral cyclobutadiene, the $\psi_{1}$ is occupied by a pair of electrons, and the $\psi_{2}$ and $\psi_{3}$ are each singly occupied (Figure $3 b$ ). It is therefore clear how distortion of the square form of cyclobutadiene to the rectangular form is preferential, since the triplet diradical can convert into a closedshell singlet (Figure 3c). However, in the case of the $6 \pi$-electron aromatic dianion, as can formally be extracted from a metal cyclobutadienyl complex, the $\psi_{1}, \psi_{2}$, and $\psi_{3}$ are each fully occupied (Figure 3d). Therefore, no distortion will occur, and this is the origin of metal stabilisation of cyclobutadiene since, formally the additional two electrons derive from the coordinated metal. ${ }^{[1,3,5]}$

The question that then naturally arises from an understanding of the $\Psi_{1}-\psi_{4}$ electronic structure of cyclobutadiene is "what is the precise nature of the bonding to any coordinated metal?". The symmetry of these orbitals makes them suited to varying extents of different metal-ligand bonding interactions: the $\psi_{1}$ for $\sigma$-bonding, the $\psi_{2}$ and $\psi_{3}$ for $\pi$-bonding, and the vacant $\psi_{4}$ for metal-ligand $\delta$ backbonding (Figure 4). ${ }^{[1,3]}$ The $\psi_{4}$ is particularly energetically high-lying, additionally, the rather small size of the $\mathrm{C}_{4}$-ring often means that, in the case of the $\delta$-bonding interaction, overlap of metal-based frontier orbitals with the $\psi_{4}$ of cyclobutadienyl may be limited due to poor spatial and energetic overlap. This is analogous to the poor $\delta$-overlap in $\mathrm{C}_{5}$-metallocenes. ${ }^{[3]}$ Resultantly, $\delta$-type bonding is generally of limited significance, and $\sigma$ - and $\pi-$ bonding interactions dominate in metal-cyclobutadienyl complexes. ${ }^{[3]}$ For comparison, due to the much greater size of the cyclooctatetraenyl $\mathrm{C}_{8}$-ring, and the low relative energies of the occupied $\delta$-symmetry $\psi_{4}$ and $\psi_{5}$ of this carbocycle, metal-ligand $\delta$-bonding is common in complexes of large metal ions with the cyclooctatetraenyl dianion. ${ }^{[13-15]}$

For the early actinides, in principle $7 s, 7 p, 6 d$, and $5 f$ orbitals are all available for bonding. ${ }^{[10,11]}$ This provides the potential for $\sigma-, \pi-$, and $\delta$-symmetry metal-ligand bonding combinations and an opportunity to draw comparisons between transition metal and actinide bonding character. Additionally the four-fold symmetric bonding combinations of cyclobutadienyl and its larger cousin cyclooctatetraenyl, from the iconic uranocene, may be 

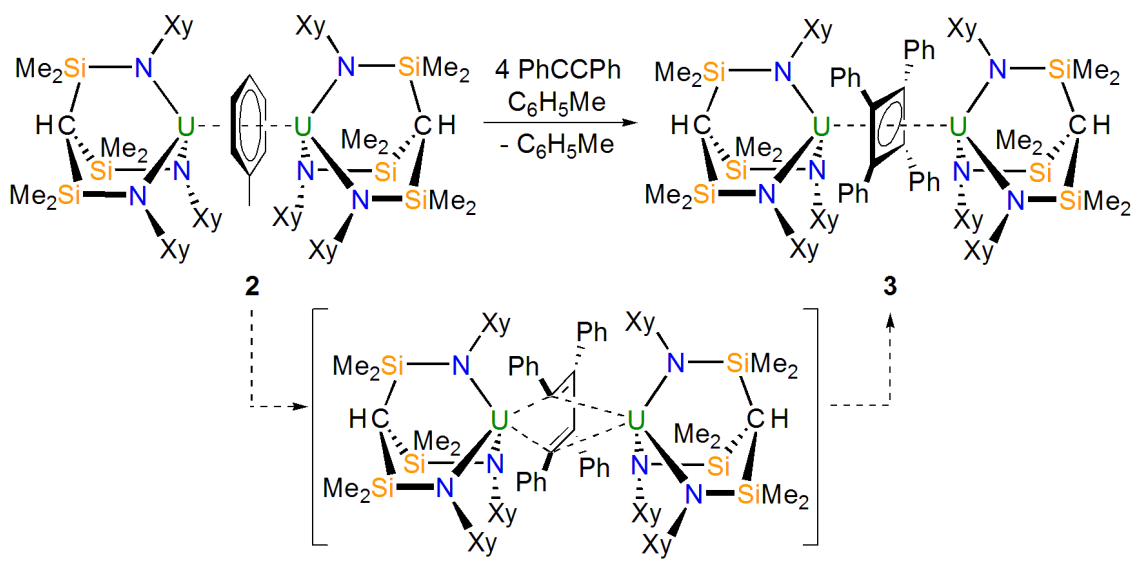

Scheme 1. Synthesis of the inverse-sandwich diuranium(IV) cyclobutadienyl complex 3 via a proposed acyclic intermediate. $\mathrm{Xy}_{2}=\mathrm{C}_{6} \mathrm{H}_{3}-3,5-\mathrm{Me}_{2}$. Note, although the U-C 4 interactions in 3 are drawn as a symmetric $\mu: \eta^{4}-\eta^{4}$ mode for clarity, the solid-state structure reveals that the bonding is effectively $\mu: \eta^{5}-\eta^{5}$ as a result of the two uranium ions being asymmetrically situated over one $\mathrm{C}-\mathrm{C}$ bond to engage in interactions to two phenyl ipso-carbon atoms.

compared. ${ }^{[13]}$ This provides a key driver for developing actinide cyclobutadienyl chemistry, since experimentally obtained examples provide opportunities to meaningfully probe the extent and nature of the metal-ligand bonding in detail. ${ }^{[14]}$

\section{Actinide-Cyclobutadienyl Complexes}

\section{An Inverse-Sandwich Diuranium(IV) Tetraphenyl- (cyclobutadienyl) Complex}

Although the structure of I was revealed in $1960,{ }^{[4 a]}$ the first $f$ element cyclobutadienyl complex was not reported until more than half a century later. ${ }^{[16]}$ In 2013 , Liddle and co-workers reported that reaction of the inverse-sandwich diuranium(V) toluene-tetraanion complex $\left[\left\{\mathrm{U}\left(\mathrm{Ts}^{\mathrm{X} y}\right)\right\}_{2}\left(\mathrm{C}_{6} \mathrm{H}_{5} \mathrm{Me}\right)\right]\left(\mathbf{2}, \mathrm{Ts}^{\mathrm{xy}}=\right.$ $\left.\mathrm{HC}\left(\mathrm{SiMe}_{2} \mathrm{NC}_{6} \mathrm{H}_{3}-3,5-\mathrm{Me}_{2}\right)_{3}\right)$ with an excess of diphenylacetylene led to formation of the inverse-sandwich diuranium(IV) tetraphenyl(cyclobutadienyl) complex $\left[\left\{\mathrm{U}\left(\mathrm{Ts}^{\mathrm{Xy}}\right)\right\}_{2}\left(\mathrm{C}_{4} \mathrm{Ph}_{4}\right)\right] \quad$ (3), Scheme $1^{[16,18]}$ Complex 3 , was prepared in $20 \%$ yield via the reductive [2 +2$]$-cycloaddition of diphenylacetylene, facilitated by the highly reducing $10 \pi$-electron toluene tetraanion and two close-proximity uranium centres of $\mathbf{2}$. The formation of $\mathbf{3}$ is rather sluggish and is proposed to progress via an intermediate complex featuring an acyclic butadiene dianion ligand. ${ }^{[19,20]}$ It is postulated that ring-closure of the acyclic species - forming a strained, charge-rich four-membered ring - takes some time highlighting the difficulties in directing ring-closing reactions in the absence of strong orbital or polarity driving forces, but is driven by the resultant aromatic stabilisation energy of the cyclobutadienyl dianion. ${ }^{[8,16]}$ Acyclic butadiene-metal complexes have been formed from the uranium(III)-mediated reductive-coupling of alkynes, and have been identified as intermediates in the formation of transition metal cyclobutadienyl complexes, such as III and IV (Figure 1). ${ }^{[5,7,19,20]}$ The steric profile of the $\left\{\mathrm{Ts}^{\mathrm{X} y}\right\}^{3-}$ ligand appears to be crucial for the formation of the carbocyclic $\left\{\mathrm{C}_{4} \mathrm{Ph}_{4}\right\}^{2-}$ dianion, and in contrast it was found that reaction of $\left[\left\{\mathrm{U}\left(\mathrm{Ts}^{\mathrm{Tol}}\right)\right\}_{2}\left(\mathrm{C}_{6} \mathrm{H}_{5} \mathrm{Me}\right)\right]\left(\mathrm{Ts}^{\mathrm{Tol}}=\mathrm{HC}\left(\mathrm{SiMe}_{2} \mathrm{NC}_{6} \mathrm{H}_{3}-4-\mathrm{Me}\right)_{3}\right)$ with an excess of diphenylacetylene led to the formation of an intractable mixture of products. ${ }^{[16]}$ Furthermore, 2 showed no reactivity towards bis(trimethylsilyl)acetylene, presumably because formation of the acyclic tetra(trimethylsilyl)butadiene dianion is not possible due to steric constraints imposed by the Ts-ligand system and bulkier, compared to $\mathrm{Ph}, \mathrm{SiMe}_{3}$ substituents. In light of the above observations, that $\mathbf{3}$ even forms is rather remarkable.

In the solid state, the tetraphenyl(cyclobutadienyl) dianion coordinates asymmetrically to the two uranium(IV) centres in $\mathbf{3}$, with both metal ions displaced towards one edge of the $C_{4}$ ring. ${ }^{[16]}$ Thus, the U-C distances span 2.655(5)-2.664(5) $\AA$ for the carbon atoms of the "close" edge of the cyclobutadienyl ring, and $2.860(6)-2.871(5) \AA$ for those of the "far" edge. Furthermore, the uranium centres appear to interact with an ipso-carbon atom of the phenyl substituents on the "close" edge of the cyclobutadienyl ligand, one to each uranium ion, with $\mathrm{U}-\mathrm{C}_{\text {ipso }}$ distances of 2.887(5) and $2.842(5) \AA$. It is noteworthy that the ${ }^{1} \mathrm{H}$ NMR spectrum of 3 in $\mathrm{C}_{6} \mathrm{D}_{6}$ suggests that this coordination mode is retained in solution. ${ }^{[16]}$ The $\mathrm{C}-\mathrm{C}$ distances between carbon atoms of the cyclobutadienyl ring (av. 1.484(12) A) are statistically indistinguishable by the $3 \sigma$-criterion, and span $1.442(8)-1.502(8)$ A.

SQUID magnetometric measurements made on powdered samples of 3 evidence the uranium(IV) oxidation state assignment for this complex. ${ }^{[16]}$ At $300 \mathrm{~K}$ the magnetic moment of 3 is $3.95 \mu_{\mathrm{B}}$, which decreases smoothly to $0.67 \mu_{\mathrm{B}}$ at $1.8 \mathrm{~K}$. Although these values are somewhat lower than that calculated for two independent uranium(IV) centres $\left(5.06 \mu_{\mathrm{B}}\right)$, there is no clear evidence for uranium $\cdots$ uranium coupling at low temperatures. ${ }^{[10,21]}$

To shed more light on the nature of the uranium-cyclobutadienyl bonding interactions in $\mathbf{3}$, unrestricted density functional theory (DFT) calculations were performed. ${ }^{[16]}$ The HOMO to HOMO-2 of 3 were found to be of essentially non-bonding $5 f$ character. The HOMO-3 is of rather low population density, but nevertheless involves a rather weak $\delta$-type donation, from $5 f / 6 d$ hybrid $(5 f: 6 d$ $95: 5 \%)$ orbitals of both uranium centres to the vacant cyclobutadienyl $\psi_{4}$ orbital $\left(25: 75 \% \mathrm{C}_{4}: U\right)$. However, the major U$\mathrm{C}_{4}$ bonding interactions are represented by HOMO-6 and HOMO7. These molecular orbitals comprise interactions between the cyclobutadienyl $\psi_{2}$ and $\psi_{3}$ orbitals and $5 f / 6 d$ hybrid orbitals of both uranium ions and are both of $\pi$-symmetry. The HOMO- 6 is composed of $73: 27 \% \mathrm{C}_{4}: \mathrm{U}$ character, and the uranium component 
$85: 15 \% 5 f: 6 d$. The uranium contribution to the HOMO-7 is slightly lower $\left(80: 20 \% \mathrm{C}_{4}: \mathrm{U}\right)$, but the $5 f / 6 d$ character of this orbital $(5 f: 6 d$ $83: 17 \%)$ is almost identical to the HOMO-6. The energetic separation of the $\delta$ - and $\pi$-type bonding molecular orbitals in $\mathbf{3}$ is $\sim 1.40 \mathrm{eV}$.

Clearly, the uranium $5 f$ orbital character is much greater than $6 d$ character in all of the abovementioned $\mathrm{U}_{-} \mathrm{C}_{4}$ bonding molecular orbitals. ${ }^{[16]}$ This may be due to the small size of the cyclobutadienyl ring and the angular nature of such bonding interactions, for which $5 f$ orbitals are better suited. ${ }^{[3,14,15]}$ However, these calculations also suggest that, as is typical of uranium, covalent contributions to the metal-ligand bonding in $\mathbf{3}$ are much smaller than the electrostatic contributions.

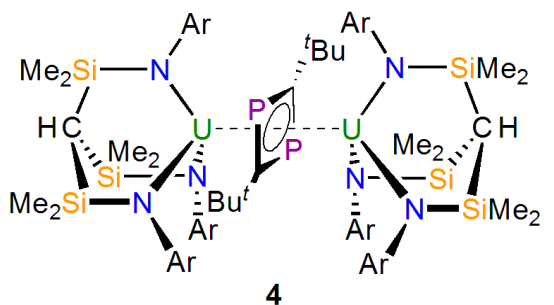

Figure 5. Diuranium(IV) diphosphacyclobutadienyl complex 4. $\mathrm{Ar}=\mathrm{C}_{6} \mathrm{H}_{4}-4-\mathrm{Me}$.

The slow formation of 3 inspired the synthesis of the related diphosphacyclobutadienyl complex $\left[\left\{\mathrm{U}\left(\mathrm{Ts}^{\mathrm{Tol}}\right)\right\}_{2}\left(\mathrm{C}_{2} \mathrm{P}_{2}{ }^{t} \mathrm{Bu}_{2}\right)\right](4)$ to test the abovementioned polarity argument. Complex 4 was prepared by reaction of $\left[\left\{\mathrm{U}\left(\mathrm{Ts}^{\mathrm{Tol}}\right)\right\}_{2}\left(\mathrm{C}_{6} \mathrm{H}_{5} \mathrm{Me}\right)\right]$ with two equivalents of $B u^{t} C \equiv P .{ }^{[16]}$ Complex $\mathbf{4}$ appears to be formed much more rapidly than 3 , which can be ascribed to the higher polarity/reactivity of the $\mathrm{C} \equiv \mathrm{P}$ bond in the phosphaalkyne. As with 3, DFT calculations indicate that the bonding in $\mathbf{4}$ is predominantly electrostatic, although weak $\delta$ - and $\pi$-type bonding interactions are also found in the HOMO-3 and HOMO-6/HOMO-7, respectively.

\section{Cyclobutadienyl Uranium(IV) Borohydride Complexes}

In 2019, the second actinide-cyclobutadienyl complex, in this case the anionic uranium(IV) half-sandwich complex $\left[\mathrm{U}\left\{\mathrm{C}_{4}\left(\mathrm{SiMe}_{3}\right)_{4}\right\}\left(\mathrm{BH}_{4}\right)_{3}\right]\left[\mathrm{Li}(\mathrm{THF})_{4}\right]$ (5) was reported by Liddle and co-workers. ${ }^{[22]}$ Pianostool complex $\mathbf{5}$ features a dianionic tetra(trimethylsilyl)cyclobutadienyl ligand, rather than the tetraphenyl-substituted variant in $3^{\left[{ }^{[16]}\right.}$ The preparation of $\mathbf{5}$ was achieved by treatment of the uranium(III) tris(borohydride) complex $\left[\mathrm{U}\left(\mathrm{BH}_{4}\right)_{3}(\mathrm{THF})_{2}\right]$ with $1 \mathrm{Li}$ (Scheme 2). ${ }^{[8,22,23]}$ This reaction results in the disproportion of uranium(III) and formation of uranium(IV) complex 5, with concomitant precipitation of 0.25 equivalents of metallic uranium. Thus, out of a theoretical maximum of $75 \%$, complex $\mathbf{5}$ is isolated in $55 \%$ crystalline yield. ${ }^{[22]}$ The use of $1 \mathbf{L i}$, which has a preformed dianionic $\mathrm{C}_{4}$ ring, enabled the synthesis of the uranium cyclobutadienyl complex, whilst circumventing the need for the metal to mediate the $[2+2]-$ cycloaddition of two alkynes. ${ }^{[8,16]}$ Indeed, in the same report, it was disclosed that the reaction of acyclic dilithiobutadiene $[\mathrm{LiC}(\mathrm{Ph}) \mathrm{C}(\mathrm{Ph}) \mathrm{C}(\mathrm{Ph}) \mathrm{C}(\mathrm{Ph}) \mathrm{Li}]$ with $\mathrm{UCl}_{4}$ led to reduction of
uranium(IV) to elemental uranium and not the desired ring-closure products, again highlighting the strongly reducing nature of these dianions and the inherent problems associated with constructing cyclobutadienyl ligands at f-element centres. ${ }^{[22]}$ Additionally, reaction of $1 \mathrm{Li}$ with $\mathrm{UCl}_{4}$ led also to uranium(IV) reduction and intractable product mixtures, hence why the halide-free uranium(III) reagent $\left[\mathrm{U}\left(\mathrm{BH}_{4}\right)_{3}(\mathrm{THF})_{2}\right]$ was employed. The emerging theme of actinide cyclobutadienyl chemistry from the synthesis of $\mathbf{5}$, and all the complexes described below, is that halides, usually the work-horse starting materials for the vast majority of synthetic actinide chemistry, have thus far not fared particularly well in this arena. Thus, the use of borohydrides, which have been known for many years but are not frequently used precursors, is notable, and highlights how crucial selecting the 'right' starting materials is to preparing and isolating actinide cyclobutadienyl complexes. Of course, this is certainly true of any metal complex synthesis generally, but it seems particularly acute for cyclobutadienyl complexes.
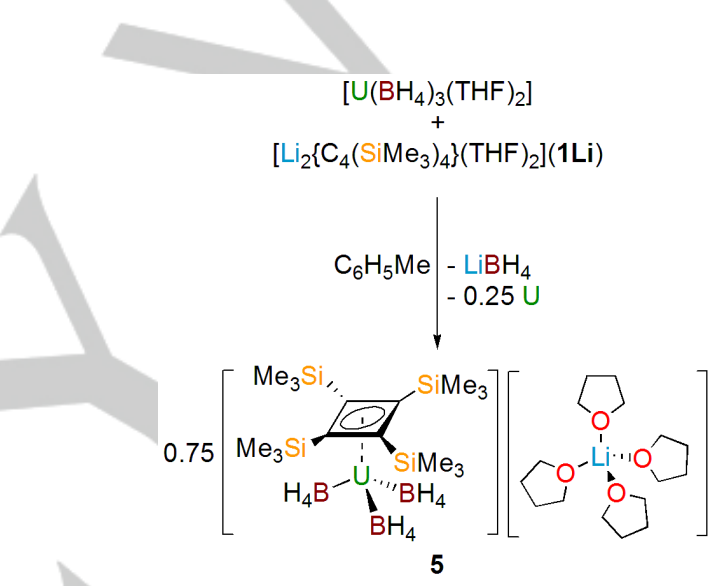

Scheme 2. Synthesis of the half-sandwich uranium(IV) cyclobutadienyl complex 5.

The terminal, rather than bridging, nature of the cyclobutadienyl ligand in $\mathbf{5}$ presented the opportunity to gain a greater insight into the $\mathrm{U}-\mathrm{C}_{4}$ bonding interaction, both crystallographically and computationally. ${ }^{[22]}$ In the solid state structure of $\mathbf{5}$, the $\left\{\mathrm{C}_{4}\left(\mathrm{SiMe}_{3}\right)_{4}\right\}^{2-}$ dianion coordinates to the uranium(IV) centre in an $\eta^{4}$-manner. The U-C distances within 5 (av. 2.513(17) $\AA$ ) are very short, and markedly shorter than those measured for 3 , spanning a narrower range of $2.477(11)-2.549(12) \AA^{\left[{ }^{[16]}\right.}$ This reflects the more symmetric coordination mode of the cyclobutadienyl ligand to uranium in $\mathbf{5}$ compared with $\mathbf{3}$, in addition to the terminal versus bridging nature of the ligand in $\mathbf{3}$ and $\mathbf{5}$, respectively. ${ }^{[16,22]}$ In the case of $\mathbf{5}$, there are no apparent interactions between ligand silyl substituents and the uranium centre. Indeed, these substituents bend out of the plane of the $\mathrm{C}_{4}$ ring, away from the uranium ion, with displacements spanning $0.452(3)-0.566(3) \AA$. This bending has been observed in other complexes of the $\left\{\mathrm{C}_{4}\left(\mathrm{SiMe}_{3}\right)_{4}\right\}^{2-}$ dianion. ${ }^{[24,25]}$ Density functional theory calculations performed on the anionic component of $\mathbf{5}$ suggest that this distortion maximises the spatial overlap of metal and cyclobutadienyl orbitals, which has also been proposed in a ruthenium derivative. ${ }^{[25]}$ The C-C distances between carbon atoms of the carbocyclic $\mathrm{C}_{4}$ ring in 5 are unremarkable, and span 1.452(16)-1.488(17) $\AA$, with an average value of $1.464(19) \AA$. The coordination sphere of the 
uranium centre is completed by three $\mathrm{K}^{3}$-tetrahydroborate groups. The $\mathrm{K}^{3}$-coordination mode of the $\left[\mathrm{BH}_{4}\right]^{-}$groups was established through a combination of crystallographic, IR spectroscopic, and DFT calculations. ${ }^{[22,26]}$

${ }^{1} \mathrm{H}$ NMR spectroscopy performed on 5 in $\mathrm{C}_{6} \mathrm{D}_{6}$ indicates that the $\eta^{4}$-coordination mode of the cyclobutadienyl ligand to uranium is maintained in solution, with the resonance corresponding to the $\mathrm{SiMe}_{3}$ groups observed at $-4.69 \mathrm{ppm} .{ }^{[22]}$ Furthermore, a very broad resonance corresponding to the $\left[\mathrm{BH}_{4}\right]^{-}$hydrides is centred at $15.97 \mathrm{ppm}$ in the ${ }^{1} \mathrm{H}$ NMR spectrum of $\mathbf{5}$. The ${ }^{7} \mathrm{Li}\left\{{ }^{1} \mathrm{H}\right\}$ NMR chemical shift $(5.93 \mathrm{ppm})$ indicates that the cation remains separated from the anionic uranium complex, even in solution. One resonance is observed in the ${ }^{11} \mathrm{~B}\left\{{ }^{1} \mathrm{H}\right\}$ NMR spectrum of 5 at $132.67 \mathrm{ppm}$.

SQUID magnetometric data was collected for 5: at $300 \mathrm{~K}$ the magnetic moment of the complex was found to be $3.03 \mu_{\mathrm{B}}$, which

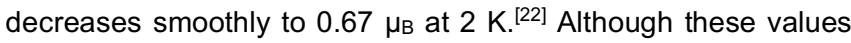
are characteristic of ${ }^{3} \mathrm{H}_{4}$ uranium(IV), the decrease in magnetic moment is less rapid than would be expected. ${ }^{[10,21]}$ This phenomenon has been previously observed for uranium(IV) complexes bearing charge-rich and -dense ligands, and is perhaps indicative of a strong interaction between the dianionic $\left[\mathrm{C}_{4}\left(\mathrm{SiMe}_{3}\right)_{4}\right]^{2-}$ ligand and the uranium centre within $5{ }^{[27]}$
LUMO $+5 .{ }^{[16,22]}$ This unoccupied orbital, involving the $\psi_{4}$ molecular orbital of cyclobutadienyl, is composed of 49:51 $\mathrm{C}_{4}: \mathrm{U}$ character, with the uranium contribution comprising 7:93 $5 f: 6 d$ character. Compared with the energetic separation of the $\delta$ - and $\pi$-type bonding molecular orbitals in $\mathbf{3}(\sim 1.40 \mathrm{eV})$, that calculated for $\mathbf{5}$ is much greater $(\sim 3.47 \mathrm{eV}) \cdot{ }^{[16,22]}$ Clearly, as with inverse-sandwich complex 3 , uranium $5 f$-orbitals contribute more significantly than $6 d$ to the $\mathrm{U}-\mathrm{C}_{4} \mathrm{\pi}$-bonding interactions. It is, however, notable that the uranium component of the virtual $\delta$-bonding combination in $\mathbf{5}$ is of almost entirely $6 d$ character, unlike 3 for which $5 f$ contributions dominate. Deep in the electronic manifold of the anion of 5 ( $\sim 18 \mathrm{eV}$ from the frontier region), the $\psi_{1}$ orbital of the cyclobutadienyl ligand in $\mathbf{5}$ engages in $\sigma$-bonding to uranium $6 d / 6 p$ hybrids. However, since both bonding and anti-bonding combination are occupied the result is that this is a net nonbonding interaction.

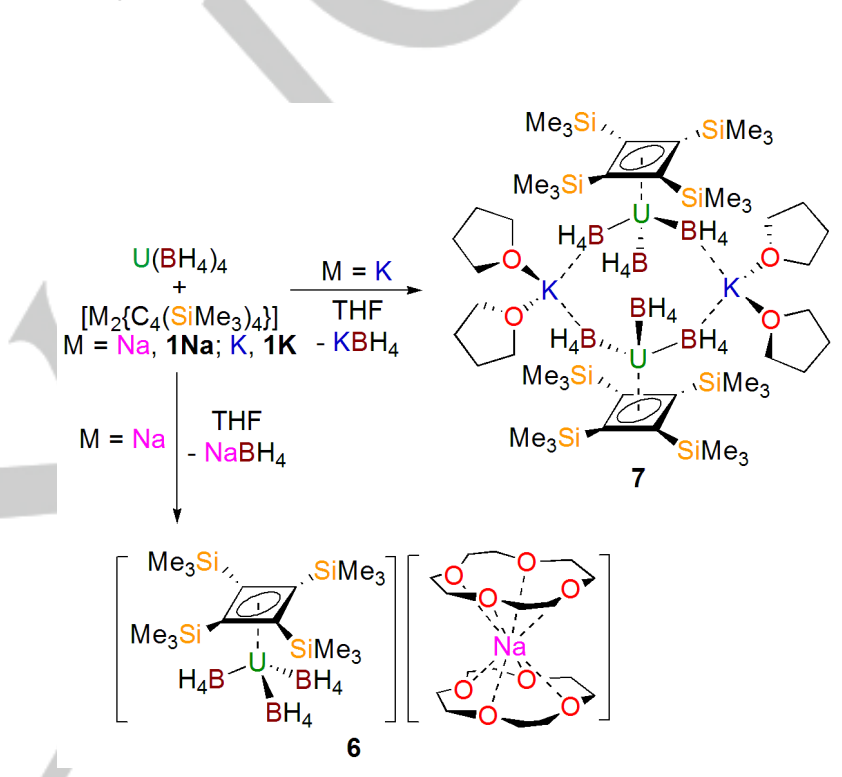

Scheme 3. Synthesis of the uranium(IV) cyclobutadienyl complexes 6 and 7 .

Figure 6. Schematic representation of one of the orbital overlaps for the uranium-cyclobutadienyl $\pi$-bonding interactions in $\mathbf{5}$. Two of the silyl groups are omitted for clarity. The second $\pi$-bonding interaction is analogous, but rotated by $90^{\circ}$ with respect to the principal rotation axis, which by convention runs along the vector that aligns with the centre of the cyclobutadienyl ring and the uranium ion.

To gain an insight into the actinide-cyclobutadienyl interaction, unrestricted DFT calculations were performed on the anionic component of $5^{[22]}$ The principle $\mathrm{U}^{\left[\mathrm{C}_{4}\right.}$ bonding orbitals are HOMO-2 and HOMO-3. These molecular orbitals are quasidegenerate, of $\pi$-symmetry and involve donation of electron density from occupied cyclobutadienyl $\psi_{2}$ and $\psi_{3}$ orbitals to vacant uranium $5 f / 6 d$ hybrid orbitals, and are certainly consistent with the silyl deviation from the $\mathrm{C}_{4}$-plane maximising orbital overlap (Figure 6). Compositionally, the two molecular orbitals are each of 70:30 $\mathrm{C}_{4}: \mathrm{U}$ character, respectively, with the uranium contribution constituted of $67: 335 f: 6 d$ character. Although for inverted sandwich complex $\mathbf{3}$ a minor $\mathrm{U}-\mathrm{C}_{4} \delta$-type bonding interaction is found by quantum chemical calculations, in the case of half-sandwich complex $\mathbf{5}$ the $\delta$-bonding orbital is found in the
Shortly after the report of $\mathbf{5}$, Layfield and co-workers reported the closely related uranium(IV) borohydride complexes $\left[\mathrm{U}\left\{\mathrm{C}_{4}\left(\mathrm{SiMe}_{3}\right)_{4}\right\}\left(\mathrm{BH}_{4}\right)_{3}\right][\mathrm{Na}(12-\mathrm{crown}-4)] \quad$ (6) and $\left[\mathrm{U}\left\{\mathrm{C}_{4}\left(\mathrm{SiMe}_{3}\right)_{4}\right\}\left(\mathrm{BH}_{4}\right)_{2}\left(\mu-\mathrm{BH}_{4}\right)\left\{\mathrm{K}(\mathrm{THF})_{2}\right\}\right]_{2}(7){ }^{[28]}$ Complexes 6 and 7 were prepared via the reaction of the tetravalent uranium starting material $\mathrm{U}\left(\mathrm{BH}_{4}\right)_{4}$ with either 0.5 equivalents of $\left[(\mathrm{Na})_{2}\left\{\mathrm{C}_{4}\left(\mathrm{SiMe}_{3}\right)_{4}\right\}(\mathrm{THF})\right]_{2} \quad(\mathbf{1 N a})$ or one equivalent of $\left[(\mathrm{K})_{2}\left\{\mathrm{C}_{4}\left(\mathrm{SiMe}_{3}\right)_{4}\right\}\right](\mathbf{1 K})$, respectively (Scheme 3). ${ }^{[17,28]}$ Complexes 6 and 7 were isolated in $69 \%$ and $21 \%$ yields, respectively. ${ }^{[28]}$ Separated-ion-pair 6 features an almost-identical anionic component to that observed within 5. ${ }^{[22]}$ Similarly, contact-ion-pair 7 also features two $\left[\mathrm{U}\left\{\mathrm{C}_{4}\left(\mathrm{SiMe}_{3}\right)_{4}\right\}\left(\mathrm{BH}_{4}\right)_{3}\right]^{-}$anions, in this case bridged by two $\left[\mathrm{K}(\mathrm{THF})_{2}\right]^{+}$cations through two $\left[\mathrm{BH}_{4}\right]^{-}$groups of each pianostool unit. Thus, the core structural parameters of 6 and $\mathbf{7}$ are very similar to those of $\mathbf{5}$, but for reference the average U-C distances measured for 7 (2.541(9) $\AA$ ), 8 (2.514(23) $\AA$ ) and 5 $(2.513(17) \AA)$ are statistically indistinguishable by the $3 \sigma-$ criterion. ${ }^{[22,28]}$ Additionally, the ${ }^{1} \mathrm{H}$ and ${ }^{11} \mathrm{~B}\left\{{ }^{1} \mathrm{H}\right\}$ NMR spectra of 6 and $\mathbf{7}$ are also very similar to those reported for $\mathbf{5}$. Finally, quantum chemical calculations performed on the uraniumcontaining fragment of 6 are consistent with those performed on the corresponding anion of $5 .{ }^{[22,28]}$ 
In addition to complexes $\mathbf{6}$ and 7, Layfield and co-workers also reported the uranium(IV) borohydride allyl/tuck-in cyclobutadienyl complex $\left[\mathrm{U}\left(\mathrm{BH}_{4}\right)\left\{\mathrm{C}_{4}\left(\mathrm{SiMe}_{3}\right)_{4}\right\}\left\{\mathrm{n}^{3}-\mathrm{C}_{4} \mathrm{H}\left(\mathrm{SiMe}_{3}\right)_{3}-\mathrm{K}-\right.\right.$ $\left.\left.\left(\mathrm{CH}_{2} \mathrm{SiMe}_{2}\right)\right\}\right]\left[\mathrm{Na}\left({ }^{\mathrm{t}} \mathrm{BuOMe}\right)_{3.6}(\mathrm{THF})_{0.4]}\right.$ (8). ${ }^{[28]}$ Complex 8, isolated in $30 \%$ crystalline yield, was synthesised via the reaction of one equivalent of dimeric $1 \mathrm{Na}$ with $\mathrm{U}\left(\mathrm{BH}_{4}\right)_{4}$, and required heating to reach completion (Scheme 4). ${ }^{[17,28]}$ The desired product of this reaction was the uranocene-analogue, homoleptic sandwich complex $\left[\mathrm{U}\left\{\mathrm{C}_{4}\left(\mathrm{SiMe}_{3}\right)_{4}\right\}_{2}\right]$. The solid state structure of $\mathbf{8}$ was determined by X-ray diffraction, revealing coordination of one $\left[\mathrm{C}_{4}\left(\mathrm{SiMe}_{3}\right)_{4}\right]^{2-}$ ligand, as well as an allylic $\left[\eta^{3}-\mathrm{C}_{4} \mathrm{H}\left(\mathrm{SiMe}_{3}\right)_{3}-\mathrm{K}-\right.$ $\left.\left(\mathrm{CH}_{2} \mathrm{SiMe}_{2}\right)\right]^{2-}$ moiety, and a tetrahydroborate anion, to uranium. ${ }^{[17,28]}$ Although the reaction was carried out in deuterated solvent, ${ }^{1} \mathrm{H}$ NMR spectroscopy confirmed that the $\mathrm{C}_{4}$-ring had been protonated, not deuterated. This suggests that a trimethylsilyl group is deprotonated by the highly Brønsted basic $\left\{\mathrm{C}_{4}\left(\mathrm{SiMe}_{3}\right)_{4}\right\}^{2-}$ dianion, forming the protonated allyl species and metallocyclic moiety, once again highlighting the predilection of such dianions to promote complicating deprotonation reactions. The U-C (cyclobutadienyl) distances in 8 range from 2.550(6) $2.649(6) \AA$ and average 2.597(10) $\AA$. This average value is statistically indistinguishable from that of 6 and 7 , but slightly longer than that measured for $5^{[22,28]}$ As observed for $\mathbf{5 - 7}$, the $\mathrm{SiMe}_{3}$ groups in 8 also bend out of the plane of the $\mathrm{C}_{4}$-ring, away from the metal centre, with deviations ranging from $0.348(9)$ to $0.828(11) \AA$. These deviations are (on average) greater, and span a much wider range, than those measured for 5-7, which is likely a result of the greater steric congestion at the $5 f$-metal ion in $\mathbf{8}$, compared with 5-7. With regards to the three U-C distances in the allyl-like fragment, two are rather short (2.638(5) and 2.635(6) $\AA$ ), and the other is somewhat longer (2.765(6) $\AA$ ), typical of a metalallyl interaction. ${ }^{[17]}$ The $\mathrm{C}-\mathrm{C}$ (cyclobutadienyl) distance are typical, ranging from $1.454(8)$ to $1.510(8) \AA{ }^{[8]}$ and the $C-C$ distances in the allyl-like $\mathrm{C}_{4}$-ring can be divided into short $(1.417(8)$ and $1.453(9) \AA$ ) and long (1.543(8) and 1.549(8) $\AA$ ) groups, which is typical of such a moiety. ${ }^{[17]}$

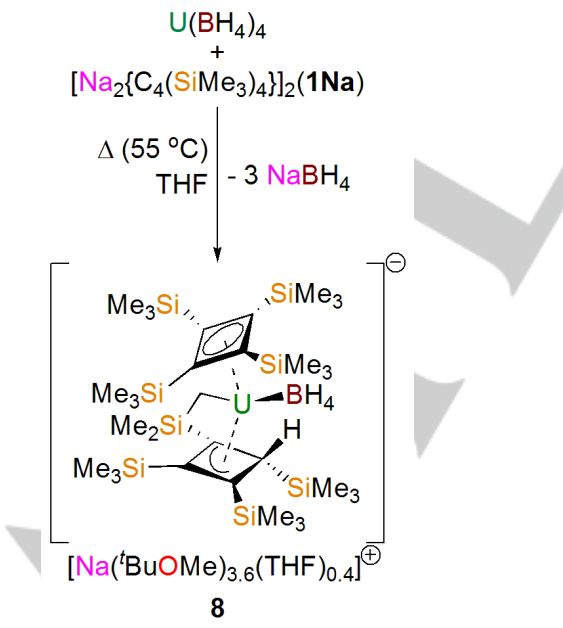

Scheme 4. Synthesis of the uranium(IV) cyclobutadienyl-allyl/cyclometallate complex 8 .

Multinuclear NMR spectroscopy indicates that the structure observed for $\mathbf{8}$ in the solid state is also maintained in solution. ${ }^{[28]}$
Five resonances, ranging from +67.53 to $258.00 \mathrm{ppm}$ are observed in the ${ }^{29} \mathrm{Si}$ DEPT90 NMR spectrum of 8 . The ${ }^{11} \mathrm{~B}\left\{{ }^{1} \mathrm{H}\right\}$ NMR spectrum of 8 features only a single resonance, at 41.60 ppm - significantly downfield from that measure for $5-7 .{ }^{[22,28]}$ The resonance corresponding to the silyl groups of the cyclobutadienyl ligand occurs at $-0.56 \mathrm{ppm}$ in the ${ }^{1} \mathrm{H}$ NMR spectrum of $\mathbf{8}$.

DFT calculations performed on the anionic component of $\mathbf{8}$, reveal that, similarly to $\mathbf{5}$ and $\mathbf{6}$, there is a significant contribution from the metal to the uranium-cyclobutadienyl and uranium-allyl $\pi-$ bonding interactions. ${ }^{[22,28]}$ However, the uranium $5 f$ and $6 d$ contributions to these molecular orbitals in $\mathbf{8}$ are similar in magnitude, unlike in $\mathbf{5}$, where $5 f$ orbital contributions dominate.

\section{A Homotrimetallic Uranium(IV)-Cyclobutadienyl Complex}

The chemistry of uranium(III) cyclooctatetraenyl-cylopentadienyl complexes is well established. ${ }^{[29]}$ Such species have displayed unique and rich reactivity with small molecules, highlighting the remarkable differences between $d$ - and $f$-block metals. There are obvious similarities between the cyclobutadienyl dianion and cyclooctatetraenyl dianion, which both possess four-fold symmetry. ${ }^{[3,13]}$ Thus, with the recent report of $\mathbf{5}$, a uranium(III) cyclobutadienyl-cyclopentadienyl complex became a synthetic target.

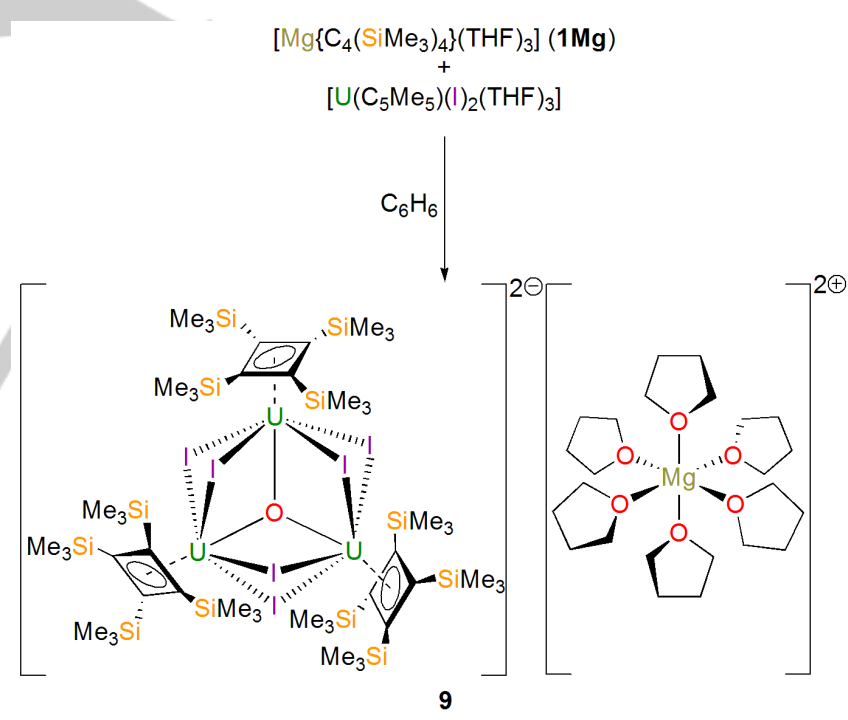

Scheme 5. Synthesis of the oxo-centred homotrimetallic uranium(IV) cyclobutadienyl complex $\mathbf{9}$.

Liddle and co-workers reported that initial attempts to synthesise such a complex via reaction of the pentamethylcyclopentadienyl uranium(III) complex $\left[\mathrm{U}\left(\mathrm{n}^{5}-\mathrm{C}_{5} \mathrm{Me}_{5}\right) \mathrm{I}_{2}(\mathrm{THF})\right]$ with $1 \mathrm{Li}$ led only to the isolation of the oxo-centred homotrimetallic uraniumpentamethylcyclopentadienyl complex $\left[\left\{U\left(\eta^{5}-C_{5} M_{5}\right)(\mu-I)_{2}\right\}_{3}\left\{\mu_{3}-\right.\right.$ O $\left.\left\{\text { Li }(\mathrm{THF})_{3}\right\}_{0.5}\right]_{2}\left[\mathrm{Li}(\mathrm{THF})_{4}\right]$ in low yield, ${ }^{[8,30,31]}$ where reductive activation of one of the THF molecules coordinated to the starting materials provides the central oxo ligand. ${ }^{[32]}$ However, it was found that reaction of $\left[\mathrm{U}\left(\eta^{5}-\mathrm{C}_{5} \mathrm{Me}_{5}\right) \mathrm{I}_{2}(\mathrm{THF})\right]$ with $\left.\left[\mathrm{Mg}_{2} \mathrm{C}_{4}\left(\mathrm{SiMe}_{3}\right)_{4}\right\}(\mathrm{THF})_{2}\right](\mathbf{1} \mathbf{M g})$ in benzene led to the formation of 
the oxo-centred homotrimetallic uranium(IV)-cyclobutadienyl complex $\left[\left\{\mathrm{U}\left(\mathrm{C}_{4}\left[\mathrm{SiMe}_{3}\right]_{4}\right)(\mu-\mathrm{I})_{2}\right\}_{3}\left\{\mu_{3}-\mathrm{O}\right\}\right]\left[\mathrm{Mg}(\mathrm{THF})_{6}\right] \quad$ (9) in $19 \%$ crystalline yield (Scheme 5). ${ }^{[24,31]}$ The reasons for the divergent reactivities displayed by $1 \mathrm{Li}$ and $1 \mathrm{Mg}$ towards $\left[\mathrm{U}\left(\eta^{5}-\right.\right.$ $\left.\left.\mathrm{C}_{5} \mathrm{Me}_{5}\right) I_{2}(\mathrm{THF})\right]$ are unclear, but are perhaps a consequence of the differing Lewis acidities of the two s-block metals.

As determined by X-ray diffraction, complex 9 features three uranium(IV) ions in a trigonal planar arrangement around a central $\mu_{3}-0 \times 0$ ligand, with two bridging $\mu$-iodide ligands between each pair of uranium centres. ${ }^{[31]}$ Therefore, all three uranium centres in 9 adopt pseudo-octahedral half-sandwich geometries, with each coordinated by four iodide ligands, the oxo ligand and an $\eta^{4}$ cyclobutadienyl ligand. The average U-C distance in 9 is 2.574(7) $\AA$; statistically indistinguishable from that measured for halfsandwich complex 5 (2.513(17) $\AA$ ), despite the differing uranium coordination environments in the two complexes. ${ }^{[22,31]}$ As found for all crystallographically characterised uraniumtetra(trimethylsilyl)cyclobutadienyl complexes, in $\mathbf{9}$ the cyclobutadienyl silyl substituents bend out of the plane of the $\mathrm{C}_{4-}$ ring, away from the coordinated uranium centre. These displacements range from $0.478(13)$ to $0.652(12) \AA$, which is a broader range than found for $5^{\left[{ }^{[22,31]}\right.}$ As with uranium borohydride complexes of the $\left\{\mathrm{C}_{4}\left(\mathrm{SiMe}_{3}\right)_{4}\right\}^{2-}$ ligand, this bending is attributed to the increased spatial overlap between the cyclobutadienyl $\psi_{2}$ and $\psi_{3}$ orbitals and the $5 f / 6 d$ uranium frontier orbitals. ${ }^{[22]}$ The cyclobutadienyl C-C distances span 1.468(10)-1.487(10) A , and are all statistically indistinguishable from one another, as well as from those in $\mathbf{5}^{[22,31]}$

Complex 9 is highly sensitive, decomposing immediately in ethereal solvents, and over the course of one week in the solid state at room temperature. ${ }^{[31]}$ Additionally, the complex is insoluble in aromatic solvents, precluding its characterisation by NMR and UV/Vis/NIR spectroscopies. However, SQUID magnetic susceptibility measurements were performed on $\mathbf{9}$. In a $0.5 \mathrm{~T}$ magnetic field at $300 \mathrm{~K}$, the magnetic moment of 9 was measured to be $5.32 \mu_{\mathrm{B}}$ (3.07 $\mu_{\mathrm{B}}$ per uranium ion), which smoothly reduces to $0.94 \mu_{\mathrm{B}}\left(0.55 \mu_{\mathrm{B}}\right.$ per uranium ion $)$ at $2 \mathrm{~K} .{ }^{[31]}$ These values are typical of ${ }^{3} \mathrm{H}_{4} 5 f^{2}$ uranium(IV) in an octahedral geometry, evidencing the oxidation state assignment of $\mathbf{9 .}^{[10,21]}$ In comparison to $\mathbf{5}$, the magnetic moment for $\mathbf{9}$ decreases more rapidly with temperature. ${ }^{[22,31]}$ This perhaps suggests a slightly weaker interaction between the cyclobutadienyl dianions and respective uranium ions in $\mathbf{9}$, compared with $\mathbf{5}$. As with diuranium complex 3 , no evidence of uranium $\cdots$ uranium coupling at low temperatures is observed for $9 .[16,31,32]$

Quantum chemical calculations performed on the dianionic component of $\mathbf{9}$ reveal that, as with $\mathbf{5}, \mathbf{6}$, and $\mathbf{8}$, the principle uranium-cyclobutadienyl bonding interactions are all of $\pi$ symmetry. ${ }^{[22,28,31]}$ In the case of $\mathbf{9}$, these interactions are found in the quasi-degenerate $\mathrm{HOMO}-6$ to $\mathrm{HOMO}-11$, and again comprise interactions between the cyclobutadienyl $\psi_{2}$ and $\psi_{3}$ and uranium $5 f / 6 d$ hybrid acceptor orbitals. The HOMO- 6 to HOMO11 are, on average, of $65: 35 \mathrm{C}_{4}: \mathrm{U}$ character, with slightly greater contribution from the metal than calculated for $\mathbf{5}$. Additionally, the uranium contribution is composed of 50:50 $5 f: 6 d$ character, which is comparable to that calculated for $\mathbf{8}$, but of significantly higher $6 d$-character/lower $5 f$-character than calculated for $\mathbf{5}$. This is likely a result of the different uranium coordination environments in the three computed structures. As with $\mathbf{5}$, the uraniumcyclobutadienyl $\delta$-bonding interactions in $\mathbf{9}$ are unoccupied, and found in the LUMO+15 to LUMO+17. ${ }^{[31]}$ Therefore, for 9, the energy gap between the orbital groups of $\pi$ - and $\delta$ - symmetry is $\sim 2.67 \mathrm{eV}$ - considerably less than the corresponding energetic separation in $5(\sim 3.47 \mathrm{eV}) .{ }^{[22]}$ Again, this variance is likely a result of the differing uranium ligand sets in $\mathbf{5}$ and $\mathbf{9}$, binding strengths of the cyclobutadienyl ligands to the uranium centres in both complexes, and $5 f / 6 d$ orbital contributions to the $\mathrm{U}-\mathrm{C}_{4}$ bonding interaction.

\section{A Cyclobutadienyl-Thorium(IV) Bent-Sandwich Complex}

To gain the greatest insight into the complexities of the actinidecyclobutadienyl bonding interaction, cyclobutadienyl complexes of other actinide metals are crucial, allowing for metrical and computational comparisons to be drawn. Indeed, as all the aforementioned actinide-cyclobutadienyl complexes are of uranium, a thorium-cyclobutadienyl complex was already conspicuous by its absence from the literature. ${ }^{[16,22,28,31]}$
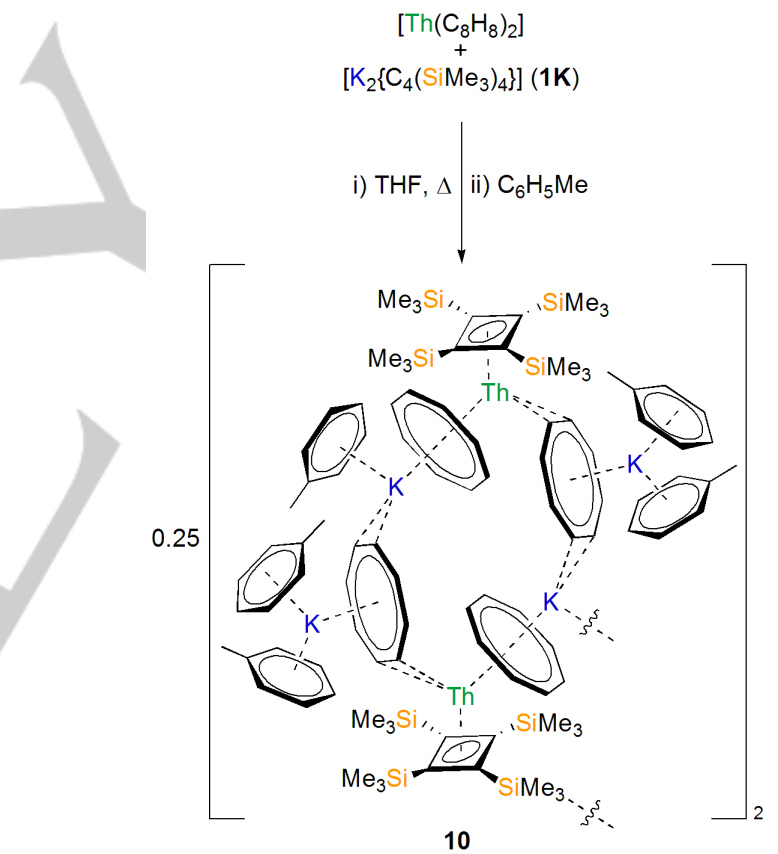

Scheme 6. Synthesis of the thorium-cyclobutadienyl complex 10.

Very recently, the synthesis of the first thorium-cyclobutadienyl complex was described by Liddle and co-workers. ${ }^{[33]}$ It was reported that the reaction between $\left[\mathrm{ThCl}_{4}(\mathrm{THF})_{3.5}\right]$ and $1 \mathrm{~K}$ led to oxidation of the $\left\{\mathrm{C}_{4}\left(\mathrm{SiMe}_{3}\right)_{4}\right\}^{2-}$ dianion to the neutral cyclobutadiene $\left\{\mathrm{C}_{4}\left(\mathrm{SiMe}_{3}\right)_{4}\right\}{ }^{[8,17,33-35]}$ Concomitantly, precipitation of a dark grey solid, assumed to be a mixture of $\mathrm{KCl}$ and colloidal thorium, was also observed. Although thorium(IV) has a much greater reduction potential $\left(E^{\theta} \mathrm{Th}(\mathrm{IV}) \rightarrow \mathrm{Th}(\mathrm{III})-3.7 \mathrm{~V}\right)$ than that of uranium(IV) $\left(E^{\theta} \mathrm{U}(\mathrm{IV}) \rightarrow \mathrm{U}(\mathrm{III})-0.6 \mathrm{~V}\right)$, this mirrors the undesirable redox chemistry observed for the reaction of $\mathrm{UCl}_{4}$ with dilithium reagent $\mathbf{1} \mathbf{L i}{ }^{[22,35]}$ Therefore, the synthetic strategy was altered, turning attention to utilising thorium(IV) complexes of carbocyclic ligands as starting materials. It was anticipated that 
these more covalent, and less polar, organothorium species would not be as prone to the same uncontrolled reduction as the less covalent and more polar thorium(IV) chloride. On the grounds of hard-soft acid-base theory, thorocene [ $\left.\mathrm{Th}\left(\eta^{8}-\mathrm{C}_{8} \mathrm{H}_{8}\right)_{2}\right]$ was selected as a starting material. ${ }^{[13,33,36]}$ It was hypothesised that displacement of the soft, charge-diffuse $\left\{\mathrm{C}_{8} \mathrm{H}_{8}\right\}^{2-}$ dianion (10Telectron, $1.25 \mathrm{e}^{-}$per carbon) by the hard, charge-concentrated $\left\{\mathrm{C}_{4}\left(\mathrm{SiMe}_{3}\right)_{4}\right\}^{2-}$ dianion (6r-electron, $1.5 \mathrm{e}^{-}$per carbon) would be favourable for the hard thorium(IV) ion. Indeed, reaction of thorocene with $1 \mathrm{~K}$, after workup, led to the isolation of brightorange thorium-cyclobutadienyl complex $\left[\left\{\mathrm{Th}\left(\eta^{4}-\mathrm{C}_{4}\left[\mathrm{SiMe}_{3}\right]_{4}\right)(\mu\right.\right.$ $\left.\left.\left.\eta^{8}-\mathrm{C}_{8} \mathrm{H}_{8}\right)\left(\mu-\eta^{2}-\mathrm{C}_{8} \mathrm{H}_{8}\right)\left(\mathrm{K}_{[}\left[\mathrm{C}_{6} \mathrm{H}_{5} \mathrm{Me}\right]_{2}\right)\right\}_{2}\left\{\mathrm{~K}\left(\mathrm{C}_{6} \mathrm{H}_{5} \mathrm{Me}\right)\right\}\{\mathrm{K}\}\right]$ (10) in $78 \%$ yield (Scheme 6). ${ }^{[33]}$

In the solid state, complex 10 crystallises with two inequivalent $\left[\mathrm{Th}\left\{\eta^{4}-\mathrm{C}_{4}\left(\mathrm{SiMe}_{3}\right)_{4}\right\}\left(\mu-\eta^{8}-\mathrm{C}_{8} \mathrm{H}_{8}\right)\left(\mathrm{u}-\eta^{2}-\mathrm{C}_{8} \mathrm{H}_{8}\right)(\mathrm{K})_{2}\right]$ groups in the crystallographic asymmetric unit. ${ }^{[33]}$ The salient structural features of each thorium-containing fragment are the $\eta^{4}$-coordination of the $\left\{\mathrm{C}_{4}\left(\mathrm{SiMe}_{3}\right)_{4}\right\}^{2-}$ dianion, in addition to two $\left\{\mathrm{C}_{8} \mathrm{H}_{8}\right\}^{2-}$ ligands to each $5 f$-metal ion. There is insufficient space in the coordination sphere of thorium to accommodate the two cyclooctatetraenyl ligands in an $\eta^{8}$-manner, in addition to the $\left\{\eta^{4}-\mathrm{C}_{4}\left(\mathrm{SiMe}_{3}\right)_{4}\right\}^{2-}$ moiety. Thus, one $\mathrm{C}_{8}$-ring coordinates the actinide ion in an $\eta^{8}$ - and the other in an unusual $\eta^{2}$-manner. Therefore, the coordination geometry around each thorium centre resembles that of a bent, heteroleptic $\mathrm{C}_{4} / \mathrm{C}_{8}$ actinocene with a coordinated alkene, the latter of which is significant because actinide-alkene interactions are virtually unknown. ${ }^{[37]}$

The average Th- $C$ (cyclobutadienyl) distances in 10 are 2.651(9) and 2.649(9) $\AA$ for the two independent thorium-cyclobutadienyl interactions; $\sim 0.14 \AA$ greater than analogous value found for 5 $(2.513(17) \AA) .{ }^{[22,33]}$ This variance is significantly larger than the $0.05 \AA$ difference in the ionic six-coordinate radii of thorium(IV) $(0.94 \AA)$ and uranium(IV) $(0.89 \AA){ }^{[38]}$ Furthermore, the Th$\mathrm{C}$ (cyclobutadienyl) distances span rather different ranges at the two independent thorium centres; 2.627(3)-2.672(3) $\AA$ and $2.557(3)-2.739(3) \AA$. These structural features perhaps reflect the fact that the bonding in $\mathbf{1 0}$ is calculated to be somewhat more ionic than in $\mathbf{5}$, but may also be a result of the very different metal coordination environments in the two complexes, as well as solidstate $\mathrm{SiMe}_{3} \cdots \mathrm{K}$ interactions. ${ }^{[2,33]}$ The average cyclobutadienyl $\mathrm{C}_{4-}$ ring C-C distances for 10 are 1.481(8) $\AA$ - statistically indistinguishable from the analogous metric for $5(1.488(17) \AA)$ and typical of a metal-coordinated tetra(trimethylsilyl)cyclobutadienyl ligand. Also noteworthy is the displacement of the cyclobutadienyl silyl substituents out of the plane of the $\mathrm{C}_{4}$-ring, away from the respective thorium centres in 10. The opposing silyl groups (i.e. 1,3 and 2,4) are displaced by similar distances, with the larger displacements ranging from $0.678(6)$ to $1.097(10) \AA$, and smaller displacements ranging from $0.097(9)$ and $0.297(8) \AA$. This differs significantly from the rather more symmetric displacements measured for $5-7 .{ }^{[22,28]}$ Again, this is likely a result of the rather different supporting ligand environments at the metal centres in $\mathbf{1 0}$ and $\mathbf{5}$, as well as the agostic-type interactions in the former. ${ }^{[22,33]}$ Finally, the $\operatorname{Cnt}\left(\eta^{8}\right.$ $\left.\mathrm{C}_{8} \mathrm{H}_{8}\right)$-Th-Cnt $\left(\eta^{4}-\mathrm{C}_{4}\left(\mathrm{SiMe}_{3}\right)_{4}\right)\left(\mathrm{Cnt}=\right.$ centroid of the $\mathrm{C}_{n}$-ring $)$ angles within 10 deviate significantly from linearity, averaging $138.1^{\circ}$ for the two inequivalent thorium-containing fragments. ${ }^{[33]}$
The UV/Vis/NIR spectrum of $\mathbf{1 0}$ is dominated by a broad charge transfer band, which spans from the visible region ( $550 \mathrm{~nm})$ into the UV. ${ }^{[33]}$ This spectrum is consistent with the intense orange colour of $\mathbf{1 0}$ in solution and the solid state. Time-dependent density functional theory (TDDFT) calculations indicate that the transition that gives 10 its colour is LMCT at $412 \mathrm{~nm}$ from the $\eta^{2}$ coordinated cyclooctatetraenyl ligand to vacant thorium $6 d$ orbitals.

The ${ }^{1} \mathrm{H}$ NMR spectrum of 10 features a sharp resonance at 0.74 ppm, corresponding to the trimethylsilyl substituents of the cyclobutadienyl ligands. Additionally, two broad resonances at 6.47 and $5.71 \mathrm{ppm}$ can be assigned to the protons of $\left[\mathrm{C}_{8} \mathrm{H}_{8}\right]^{2-}$ dianions, indicating that there are two cyclooctatetraenyl environments in solution, as well as the solid-state.

Quantum chemical calculations were performed on the [Th $\left\{\eta^{4}-\right.$ $\left.\left.\mathrm{C}_{4}\left(\mathrm{SiMe}_{3}\right)_{4}\right\}\left(\eta^{8}-\mathrm{C}_{8} \mathrm{H}_{8}\right)\left(\eta^{2}-\mathrm{C}_{8} \mathrm{H}_{8}\right)\right]^{2-}$ dianion to obtain a qualitative picture of the bonding in 10. ${ }^{[33]}$ The thorium-cyclobutadienyl and cyclooctatetraenyl bonding interactions are mixed across the HOMO-2 to HOMO-5 of the calculated structure. However, the thorium-cyclobutadienyl interactions are clearly of $\pi$-symmetry. The LUMO of $\left.\mathrm{Th}\left\{\eta^{4}-\mathrm{C}_{4}\left(\mathrm{SiMe}_{3}\right)_{4}\right\}\left(\eta^{8}-\mathrm{C}_{8} \mathrm{H}_{8}\right)\left(\eta^{2}-\mathrm{C}_{8} \mathrm{H}_{8}\right)\right]^{2-}$ is the thorium-cyclobutadienyl $\delta$-bonding interaction. Further calculations were performed on a neutral, bent [Th\{ $\eta^{4}-$ $\left.\left.\mathrm{C}_{4}\left(\mathrm{SiMe}_{3}\right)_{4}\right\}\left(\eta^{8}-\mathrm{C}_{8} \mathrm{H}_{8}\right)\right]$ species, with the $\left\{\eta^{2}-\mathrm{C}_{8} \mathrm{H}_{8}\right\}^{2-}$ moiety omitted. ${ }^{[33]}$ In this structure the two thorium-cyclobutadienyl חbonds (quasi-degenerate $\mathrm{HOMO}$ and $\mathrm{HOMO}-1$ ) were each calculated to be of $22: 78 \%$ Th:C character, with the thorium component composed of $31: 69 \% 5 f: 6 d$ character. For thorium, the $5 f$ orbitals are somewhat higher in energy than the $6 d$ orbitals, compared with uranium, for which the $5 f$ and $6 d$ orbitals are relatively similar in energy. ${ }^{[10]}$ Thus, in the case of 10 , the $5 f$ character of the thorium-cyclobutadienyl bonding interaction is higher than might have been predicted. This perhaps reflects the angular requirements for overlap with the small cyclobutadienyl $\psi_{2}$ and $\psi_{3}$ orbitals. ${ }^{[3]}$ Additionally, and in line with established knowledge of actinide bonding, the thorium-cyclobutadienyl interaction appears to be more polarised than the tetra(trimethylsilyl)cyclobutadienyl-uranium complexes discussed here. ${ }^{[10,22,33]}$

\section{Summary and Outlook}

The first transition metal-cyclobutadienyl complexes were synthesised and studied in the 1960s. ${ }^{[4,5,7]}$ These complexes advanced the collective theoretical understanding of transition metal bonding, as well as of aromatic carbocycles. ${ }^{[3,8]}$ Historically, the chemistry of the actinide metals has lagged behind that of the transition metals. ${ }^{[10]}$ Indeed, the first actinide cyclobutadienyl complex was not reported until 2013.[16] However, very recently there has been a flurry of activity in this area, with actinide cyclobutadienyl inverted-sandwich, half-sandwich, and heteroleptic sandwich complexes all now reported. ${ }^{[22,28,31,33]}$

From a synthetic perspective, several themes have already clearly emerged in this actinide cyclobutadienyl chemistry, unequivocally demonstrating that installing these small, chargerich $\mathrm{C}_{4}$-carbocycles at early actinides presents quite unusual and demanding challenges in comparison to more established $\mathrm{C}_{5-8}$ 
systems. ${ }^{[15]}$ Executing [2 + 2]-cycloadditions at transition metals, the classical example being III, is actually not that straightforward, so effecting the same chemistry at actinides that enforce far less orbital control is even more challenging. Thus, even though [ $2+$ 2]-cycloaddition to give $\left\{\mathrm{C}_{4} \mathrm{Ph}_{4}\right\}^{2-}$ has been accomplished in the synthesis of $3{ }^{[16]}$ it is so far a unique case and quite specific. Indeed, analogous attempts to construct $\left\{\mathrm{C}_{4}\left(\mathrm{SiMe}_{3}\right)_{4}\right\}^{2-}$ with the same method were unsuccessful, and this approach is not yet mature enough to be routinely designed and executed. ${ }^{[16]}$ Installation of a preformed $\mathrm{C}_{4}$-ring is emerging as the method of choice, however this has inherent challenges too. ${ }^{8}$ The $\left\{\mathrm{C}_{4}\left(\mathrm{SiMe}_{3}\right)_{4}\right\}^{2-}$ dianion is strongly reducing, so often reactions involving actinide halides have resulted in unwanted metal reductions which have frustrated synthetic efforts. ${ }^{[2,33]}$ Indeed, the fact that $\left\{\mathrm{C}_{4}\left(\mathrm{SiMe}_{3}\right)_{4}\right\}^{2-}$ can reduce thorium(IV) is a testament to its reducing power, and perhaps this dianion could find creative use as a soluble reductant more widely. ${ }^{[33]}$ The $\left\{\mathrm{C}_{4}\left(\mathrm{SiMe}_{3}\right)_{4}\right\}^{2-}$ dianion has also displayed significant Brønsted basicity, which can further complicate synthetic efforts. ${ }^{[17,28]}$ One surprising feature of actinide cyclobutadienyl chemistry so far has been the difficulties encountered in using actinide halides as starting materials. A common theme running through the compounds described above is that where halides failed, borohydride or carbocyclic precursors succeeded. ${ }^{[22,31,33]}$ Actinide borohydrides have been known for many years, but they are used infrequently in synthetic actinide chemistry and halides account for the vast majority of synthetic protocols, so this dichotomy for cyclobutadienyl systems is notable.

In all structures examined by DFT calculations, polarised $\pi$ bonding interactions involving donation from the $\psi_{2}$ and $\psi_{3}$ molecular orbitals to actinide hybrid $5 f / 6 d$ orbitals have been observed. ${ }^{[22,28,31,33]}$ This work has illustrated that the $5 f$-orbitals are particularly well suited to angular interactions with spatiallyconcentrated ligand orbitals. For uranium and thorium, $5 f$-orbital contributions to metal-cyclobutadienyl bonding are higher than is generally observed for bonding interactions involving these metals. ${ }^{[14]}$ Importantly, for the first time, the interaction between the cyclobutadienyl $\pi-$, and metal f-orbital, manifolds have been studied experimentally and computationally, confirming the dominance of $\pi$-bonding, but weak $\delta$-bonding in bridging species. ${ }^{[1,3]}$ Additionally, quantum chemical calculations have provided an insight into the energetic separation of the cyclobutadienyl $\psi_{2} / \psi_{3}$ and $\psi_{4}$ molecular orbitals upon complexation of the dianion to electropositive metals. As an aside, since quantum chemical calculations have played a significant role in the characterisation of the actinide-cyclobutadienyl complexes reviewed here, DFT has historically been, and remains, a very useful approach for giving insight into the ground state bonding of actinide complexes. ${ }^{[39]}$ This is especially the case when coupled to NBO and QTAIM analyses, since DFT can often give results that are consistent with multi-reference methods such as CASSCF and CASPT2, ${ }^{40]}$ which become the methods of choice for computing excited states and magnetism.

So what does the future hold? Currently, there are six uraniumand one thorium-cyclobutadienyl complexes, and one uraniumdiphosphacyclobutadienyl variant. Clearly, therefore, there is much to do, and a more diverse range of cyclobutadienyl substituent patterns would bring synthetic flexibility and tunability. Inverse-sandwich, half-sandwich pianostool, and heteroleptic sandwich classes have been reported, but a homoleptic uranium cyclobutadienyl sandwich, a 'miniature uranocene', has thus far remained elusive and constitutes an important target. The range of heteroleptic uranium cyclobutadienyl sandwich complexes can also be significantly expanded from the current $\mathrm{C}_{4 / 3}$ combination to include $\mathrm{C}_{5-8}$ carbocycles. ${ }^{[28]}$ The sole thorium cyclobutadienyl complex reported to date is a heteroleptic $\mathrm{C}_{4 / 8}$ actinocene sandwich, so there are many thorium inverse-sandwich, halfsandwich, and homo- and heteroleptic sandwich combinations that can be realised. ${ }^{[33]}$ Lastly, the greatest understanding of actinide chemistry will not emerge from just studying uranium and thorium alone. Extending actinide-cyclobutadienyl chemistry to involve transuranic elements such as neptunium, plutonium, americium, berkelium, and californium has the potential to reveal fascinating bonding, spectroscopic, magnetic, and reactivity periodic trends, furthering our knowledge and understanding of the nature and variance of covalency and $5 f / 6 d$ orbital contributions to chemical bonding across the actinide series. ${ }^{[1]}$

\section{Acknowledgements}

We thank the Royal Society, Engineering and Physical Sciences Research Council, European Research Council, University of Manchester, and National Nuclear Laboratory for past and current support of our research.

Keywords: Actinides • Cyclobutadienyl • Organometallics • Uranium • Thorium

[1] H. C. Longuet-Higgins, L. E. Orgel, J. Chem. Soc. 1956, 1969.

[2] a) C. Y. Lin, A. Krantz, J. Chem. Soc., Chem. Commun. 1972, 1111; b) O. L. Chapman, C. L. Mcintosh, J. Pacansky, J. Am. Chem. Soc. 1973 , 95, 614.

[3] S. Y. Chu, R. Hoffmann, J. Phys. Chem. 1982, 86, 1289.

[4] a) R. P. Dodge, V. Schomaker, Nature 1960, 186, 798; b) G. F. Emerson, L. Watts, R. Pettit, J. Am. Chem. Soc. 1965, 87, 131.

[5] A. Efraty, Chem. Rev. 1977, 77, 691.

[6] M. D. Rausch, R. A. Genetti, J. Am. Chem. Soc. 1967, 89, 5502.

[7] a) J. R. Fritch, K. P. C. Vollhardt, M. R. Thompson, V. W. Day, J. Am. Chem. Soc. 1979, 101, 2768; b) D. Seyferth, Organometallics 2003, 22, 2; c) C. Yu, W. -X. Zhang, Z. Xi, Organometallics 2018, 37, 4100.

[8] a) A. Sekiguchi, T. Matsuo, H. Watanabe, J. Am. Chem. Soc. 2000, 122, 5652; b) A. Sekiguchi, M. Tanaka, T. Matsuo, H. Watanabe, Angew. Chem. Int. Ed. 2000, 40, 1675; c) A. Sekiguchi, T. Matsuo, H. Watanabe, M. Nakamoto, Russ. Chem. Bull. 2004, 53, 1109.

[9] a) H. H. Dam, D. N. Reinhoudt, W. Verboom, Chem. Soc. Rev. 2007, 36, 367; b) Z. Kolarik, Chem. Rev. 2008, 108, 4208; c) P. J. Panak, A. Geist, Chem. Rev. 2013, 113, 1199; c) C. Walther, M. A. Denecke, Chem. Rev. 2013, 113, 995; d) M. Altmaier, X. Gaona, T. Fanghänel, Chem. Rev. 2013, 113, 901.

[10] S. T. Liddle, Angew. Chem. Int. Ed. 2015, 54, 8604.

[11] a) The f Elements (Eds.: N. Kaltsoyannis, P. Scott), Oxford University Press, Oxford, 1999; b) Lanthanide and Actinide Chemistry (Ed.: S. Cotton), Wiley, Chichester, 2006.

[12] a) L. T. Reynolds, G. Wilkinson, J. Inorg. Nucl. Chem. 1956, 2, 246. b) M. Cesari, U. Pedretti, A. Zazzetta, G. Lugli, W. Marconi, Inorg. Chim. Acta 1971, 5, 439; c) M. Tsutsui, N. Ely, R. Dubois, Acc. Chem. Res. 1976, 9, 217; d) T. J. Marks, Acc. Chem. Res. 1976, 9, 223; e) T. Arliguie, M. Lance, M. Nierlich, J. Vigner, M. Ephritikhine, Chem. Commun. 1995, 183.

[13] A. Streitwieser, U. Müller-Westerhoff, J. Am. Chem. Soc. 1968, 90, 7364; b) A. Avdeef, K. N. Raymond, K. O. Hodgson, A. Zalkin, Inorg. Chem. 1972, 11, 1083; c) D. Seyferth, Organometallics 2004, 23, 3562. 
[14] a) C. J. Burns, B. E. Bursten, Comments Inorg. Chem. 1989, 9, 61; b) S. A. Kozimor, P. Yang, E. R. Batista, K. S. Boland, C. J. Burns, D.L. Clark S.D. Conradson, R.L. Martin, M.P. Wilkerson, L. E. Wolfsberg, J. Am. Chem. Soc. 2009, 131, 12125; c) M. J. Tassell, N. Kaltsoyannis, Dalton Trans. 2010, 39, 6719; d) I. Kirker, N. Kaltsoyannis, Dalton Trans. 2011, 40, 124; e) N. Kaltsoyannis, Inorg. Chem. 2013, 52, 3407; f) M. L. Neidig D. L. Clark, R. L. Martin, Coord. Chem. Rev. 2013, 257, 394; g) S. G. Minasian, J. M. Keith, E. R. Batista, K. S. Boland, D. L. Clark, S. A Kozimor, R. L. Martin, D. K. Shuh, T. Tyliszczak, Chem. Sci. 2014, 5 351; h) A. Kerridge, RSC Adv. 2014, 4, 12078; i) M. P. Kelley, J. Su, M. Urban, M. Luckey, E. R. Batista, P. Yang, J. C. Shafer, J. Am. Chem. Soc. 2017, 139, 9901; j) G. Ganguly, D.-C. Sergentu, J. Autschbach, Chem. Eur. J. 2020, 26, 1776.

[15] Representative reviews: a) S. Arndt, J. Okuda, Chem. Rev. 2002, 102, 1953; b) M. N. Bochkarev, Chem. Rev. 2002, 102, 2089; c) W. J. Evans, B. L. Davis, Chem. Rev. 2002, 102, 2199; d) W. J. Evans, Inorg. Chem. 2007, 46, 3435; e) Organometallic and Coordination Chemistry of the Actinides (Eds: T. E. Albrecht-Schmitt), Springer, Berlin, Heidelberg, 2008; f) F. T. Edelmann, Coord. Chem. Rev. 2009, 256, 1151; g) F. T. Edelmann, Coord. Chem. Rev. 2010, 23-24, 2641; h) F. T. Edelmann, Coord. Chem. Rev. 2012, 261, 73; i) F. T. Edelmann, Coord. Chem. Rev. 2013, 284, 124; j) M. Ephritikhine, Organometallics 2013, 32, 2464; k) F. T. Edelmann, Coord. Chem. Rev. 2014, 306, 346; I) F. T. Edelmann Coord. Chem. Rev. 2015, 318, 29; m) S. T. Liddle, Coord. Chem. Rev. 2015, 293-294, 211; n) W. J. Evans, Organometallics 2016, 35, 3088; o) F. T. Edelmann, Coord. Chem. Rev. 2016, 338, 27; p) F. T. Edelmann, Coord. Chem. Rev. 2017, 370, 129; q) O. Walter, Chem. Eur. J. 2019 25, 2927.

[16] D. Patel, J. McMaster, W. Lewis, A. J. Blake, S. T. Liddle, Nat. Commun. 2013, 4, 2323

[17] a) B. M. Day, F. -S. Gui, S. R. Giblin, A. Sekiguchi, A. Mansikkamäki, R. A. Layfield, Chem. Eur. J. 2018, 24, 16779; b) A. Chakraborty, B. M. Day, J. P. Durrant, M. He, J. Tang, R. A. Layfield, Organometallics, 2020, 39, 8; c) J. P. Durrant, J. Tang, A. Manskikkamäki, R. A. Layfield, Chem. Commun. 2020, 56, 4708.

[18] D. Patel, F. Moro, J. McMaster, W. Lewis, A. J. Blake, S. T. Liddle, Angew. Chem. Int. Ed. 2011, 50, 10388.

[19] a) B. Kosog, C. E. Kefalidis, F. W. Heinemann, L. Maron, K. Meyer, J. Am. Chem. Soc. 2012, 134, 12792; b) R. J. Batrice, J. McKinven, P.L. Arnold, M. S. Eisen, Organometallics 2015, 34, 4039; c) L. Zhang, G. Hou, G. Zi, W. Ding, M. D. Walter, J. Am. Chem. Soc. 2016, 138, 5130 d) B. Fang, G. Hou, G. Zi, W. Ding, M. D. Walter, Organometallics 2016 $35,1384$.

[20] L. F. Veiros, G. Dazinger, K. Kirchner, M. J. Calhorda, R. Schmid, Chem. Eur. J. 2004, 10, 5860

[21] a) I. Castro-Rodríguez, K. Meyer, Chem. Commun. 2006, 1353; b) D. R. Kindra, W. J. Evans, Chem. Rev. 2014, 114, 8865.

[22] J. T. Boronski, L. R. Doyle, J. A. Seed, A. J. Wooles, S. T. Liddle, Angew. Chem. Int. Ed. 2020, 59, 295.

[23] P. L. Arnold, C. J. Stevens, J. H. Farnaby, M. G. Gardiner, G. S. Nichol, J. B. Love, J. Am. Chem. Soc. 2014, 136, 10218.

[24] K. Takanashi, A. Inatomi, V. Y. Lee, M. Nakamoto, M. Ichinohe, A. Sekiguchi, Eur. J. Inorg. Chem. 2008, 1752.

[25] K. Takanashi, V. Y. Lee, A. Sekiguchi, Organometallics 2009, 28, 1248.

[26] T. J. Marks, J. R. Kolb, Chem. Rev. 1977, 77, 263.

[27] a) D. Patel, F. Moro, J. McMaster, W. Lewis, A. J. Blake, S. T. Liddle, Angew. Chem. Int. Ed. 2011, 50, 10388; b) J. L. Brown, S. Fortier, R. A Lewis, G. Wu, T. W. Hayton, J. Am. Chem. Soc. 2012, 134, 15468; c) D. Patel, F. Tuna, E. J. L. McInnes, W. Lewis, A. J. Blake, S. T. Liddle, Angew. Chem. Int. Ed. 2013, 52, 13334; d) D. M. King, J. McMaster, F. Tuna, E. J. L. McInnes, W. Lewis, A. J. Blake, S. T. Liddle, J. Am. Chem. Soc. 2014, 136, 5619; e) D. P. Halter, H. S. La Pierre, F. W. Heinemann, K. Meyer, Inorg. Chem. 2014, 53, 8418; f) B. M. Gardner, G. Balázs, M. Scheer, F. Tuna, E. J. L. McInnes, J. McMaster, W. Lewis, A. J. Blake, S. T. Liddle, Nat. Chem. 2015, 7, 582; g) M. Gregson, E. Lu, D. P. Mills, F. Tuna, E. J. L. Mclnnes, C. Hennig, A. C. Scheinost, J. McMaster, W. Lewis, A. J. Blake, A. Kerridge, S. T. Liddle, Nat. Commun. 2017, 8, 14137; h) T. M. Rookes, B. M. Gardner, G. Balázs, M. Gregson, F. Tuna A. J. Wooles, M. Scheer, S. T. Liddle, Angew. Chem. Int. Ed. 2017, 56,
10495; i) E. Lu, J. T. Boronski, M. Gregson, A. J. Wooles, S. T. Liddle, Angew. Chem. Int. Ed. 2018, 57, 5506; j) E. Lu, A. J. Wooles, M. Gregson, P. J. Cobb, S. T. Liddle, Angew. Chem. Int. Ed. 2018, 57, 6587.

[28] N. Tsoureas, A. Mansikkamäki, R. A. Layfield, Chem. Commun. 2020, $56,944$.

[29] a) O. T. Summerscales, F. G. N. Cloke, P. B. Hitchcock, J. C. Green, N. Hazari, Science 2006, 311, 829; c) O. T. Summerscales, F. G. N. Cloke, P. B. Hitchcock, J. C. Green, N. Hazari, J. Am. Chem. Soc. 2006, 128, 9602; d) A. S. Frey, F. G. N. Cloke, P. B. Hitchcock, I. J. Day, J. C. Green, G. Aitken, J. Am. Chem. Soc. 2008, 130, 13816; e) Z. E. Button, J. A. Higgins, M. Suvova, F. G. N. Cloke, S. M. Roe, Dalton Trans. 2015, 44, 2588; f) N. Tsoureas, A. F. R. Kilpatrick, C. J. Inman, F. G. N. Cloke, Chem. Sci. 2016, 7, 4624.

[30] L. R. Avens, C. J. Burns, R. J. Butcher, D. L. Clark, J. C. Gordon, JA. R. Schake, B. L. Scott, J. G. Watkin, B. D. Zwick, Organometallics 2000, 19, 451.

[31] J. T. Boronski, L. R. Doyle, A. J. Wooles, J. A. Seed, S. T. Liddle, Organometallics 2020, 39, 1824.

[32] C. P. Larch, F. G. N. Cloke, P. B. Hitchcock, Chem. Commun. 2008, 82.

[33] J. T. Boronski, A. J. Wooles, S. T. Liddle, Chem. Sci. 2020, 11, in press.

[34] T. Cantat, B. L. Scotta and J. L. Kiplinger, Chem. Commun. 2010, 46, 919.

[35] L. J. Nugent, R. D. Baybarz, J. L. Burnett and J. L. Ryan, J. Phys. Chem. 1973, 77, 1528

[36] A. Streitwieser, N. Yoshida, J. Am. Chem. Soc. 1969, 91, 7528.

[37] A reduced 1,2-ethanediide (a doubly-reduced alkene) has been reported: N. Tsoureas, L. Maron, A. F. R. Kilpatrick, R. A. Layfield, F. G. N. Cloke, J. Am. Chem. Soc. 2020, 142, 89.

[38] G. R. Choppin, Radiochim. Acta 1983, 32, 43.

[39] N. Kaltsoyannis, Chem. Eur. J. 2018, 24, 2815.

[40] B. Vlaisavljevich, P. L. Diaconescu, W. L. Lukens, L. Gagliardi, C. C. Cummins, Organometallics 2013, 32, 1341.

[41] a) P. L. Arnold, M. S. Dutkiewicz, O. Walter, Chem. Rev. 2017, 117, 11460; b) C. Goodwin, J. Su, T. Albrecht-Schmitt, A. Blake, E. Batista, S. Daly, S. Dehnen, W. Evans, A. Gaunt, S. Kozimor, N. Lichtenberger, B. Scott, P. Yang, Angew. Chem. Int. Ed. 2019, 58, 11695. 


\section{Entry for the Table of Contents}

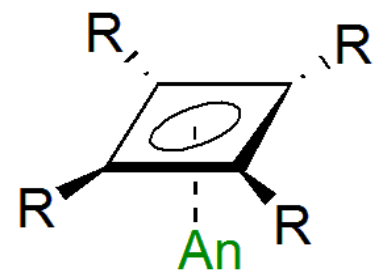

Actinide Organometallics. This Minireview, on the emerging area of actinide cyclobutadienyl chemistry, addresses bonding considerations for the cyclobutadienyl ligand, surveys synthetic routes to crystallographically authenticated actinide cyclobutadienyl complexes and their novel bonding features, and highlights future directions that merit development. 